Illinois State University

ISU ReD: Research and eData

Theses and Dissertations

3-15-2016

\title{
Token Female Police Officers or Police Exemplars: An Evaluation of the Theory of Tokenism
}

Cameron Michael Harper

Illinois State University, cameronmichaelharper@gmail.com

Follow this and additional works at: https://ir.library.illinoisstate.edu/etd

Part of the Criminology Commons, Criminology and Criminal Justice Commons, and the Quantitative, Qualitative, Comparative, and Historical Methodologies Commons

\section{Recommended Citation}

Harper, Cameron Michael, "Token Female Police Officers or Police Exemplars: An Evaluation of the Theory of Tokenism" (2016). Theses and Dissertations. 507.

https://ir.library.illinoisstate.edu/etd/507

This Thesis is brought to you for free and open access by ISU ReD: Research and eData. It has been accepted for inclusion in Theses and Dissertations by an authorized administrator of ISU ReD: Research and eData. For more information, please contact ISUReD@ilstu.edu. 


\title{
TOKEN FEMALE POLICE OFFICERS OR POLICE EXEMPLARS:
}

\section{AN EVALUATION OF THE THEORY OF TOKENISM}

\author{
Cameron M. Harper
}

\section{Pages}

Despite gains in the percentage of female police officers over past decades, female police officers are vastly underrepresented in modern policing. Female police officers face barriers to integration into policing and the surrounding culture that male police officers do not face, including unbalanced physical testing, double standards for success, and others. One explanation for the different experiences of female police officers compared to male police officers is the token status of women in policing. Instead of taking the token status of female police officers for granted, this study explored the utility of the theory of tokenism (Kanter, 1977) in explaining the experiences of female police officers in Midwestern police agencies. This is accomplished by looking for the presence of the three constructs of tokenism (visibility, contrast, and assimilation) in the accounts of 37 female police officers.

KEYWORDS: Female Police Officers, Policing, Tokenism, Tokens 
TOKEN FEMALE POLICE OFFICERS OR POLICE EXEMPLARS: AN EVALUATION OF THE THEORY OF TOKENISM

CAMERON M. HARPER

A Thesis Submitted in Partial

Fulfillment of the Requirements for the Degree of

MASTER OF SCIENCE

Department of Criminal Justice Sciences

ILLINOIS STATE UNIVERSITY

2016 
(C) 2016 Cameron M. Harper 
TOKEN FEMALE POLICE OFFICERS OR POLICE EXEMPLARS: AN EVALUATION OF THE THEORY OF TOKENISM

CAMERON M. HARPER

COMMITTEE MEMBERS:

Cara Rabe-Hemp, Chair

Ralph Weisheit

Dawn Beichner 


\section{ACKNOWLEDGMENTS}

I would like to first thank my family for everything and more than I could ever express in as short a work as this. I would also like Dr. Cara Rabe-Hemp for years of support, never giving up, always being there for ideas and critiques, pushing me to complete this work, and for the inspiration to finish and move on to the next step in my life. Next, the author would also like to thank Dr. Ralph Weisheit for teaching me the value of multiple choice tests, showing me his masterful genius in chaotic organization, and having fun with hypocrisy. I would to thank Dr. Dawn Beichner for her advice while editing this study, along with the insights from her classes that I needed to channel for the voice of this work. I would like to also thank the entire Criminal Justice Sciences faculty and staff at Illinois State University. I believe I gained an unsurpassed education from my professors and unrivaled support from office staff to advisors. Finally I would like to thank the late Dr. L. Edward Wells for the time I spent listening to his insights and intellect between classes. It was time well spent.

C. M. H. 


\section{CONTENTS}

Page

ACKNOWLEDGMENTS $\quad$ i

CONTENTS $\quad$ ii

CHAPTER

I. THE PROBLEM AND ITS BACKGROUND 1

Statement of the Problem 1

Summary 5

II. REVIEW OF RELATED LITERATURE 6

General Literature Review $\quad 6$

History of Women in Policing $\quad 7$

$\begin{array}{ll}\text { The First Policewoman } & 7\end{array}$

The Police Matron $\quad 7$

The Origin of the Policewoman 8

$\begin{array}{ll}\text { Changes after WWII } & 10\end{array}$

Current State of Women in Policing 11

What Departments Hire Women 12

Size of Department $\quad 12$

Percentage of Women at a Police Department 12

Integration and Socialization into Policing 13

Barriers to Hiring 13

Unsuccessful Integration and Voluntary Resignation 18

Ways to Assist Female Promotion $\quad 22$

$\begin{array}{ll}\text { Theoretical Framework } & 26\end{array}$

$\begin{array}{ll}\text { Three Pillars of Tokenism } & 27\end{array}$ 
$\begin{array}{ll}\text { Summary } & 30\end{array}$

III. RESEARCH DESIGN 32

Purpose $\quad 32$

$\begin{array}{ll}\text { Study Design } & 32\end{array}$

Constructs 33

Visibility and Performance Pressure 33

Contrast and Social Isolation $\quad 35$

$\begin{array}{ll}\text { Assimilation and Role Encapsulation } & 37\end{array}$

Analysis $\quad 39$

Research Questions $\quad 39$

Visibility and Performance Pressure $\quad 39$

Contrast and Social Isolation $\quad 40$

Assimilation and Role Encapsulation $\quad 40$

$\begin{array}{ll}\text { Summary } & 41\end{array}$

IV. RESULTS 43

Research Questions and Findings 43

Question 1 - Visibility and Performance Pressure 43

Question 2 - Contrast and Social Isolation 52

Question 3-Assimilation and Role Encapsulation 62

V. CONCLUSIONS, LIMITATIONS, AND IMPLICATIONS 72

Conclusions $\quad 73$

Limitations $\quad 77$

$\begin{array}{ll}\text { Implications } & 78\end{array}$

$\begin{array}{ll}\text { REFERENCES } & 81\end{array}$ 


\section{CHAPTER I}

\section{THE PROBLEM AND ITS BACKGROUND}

\section{Statement of the Problem}

Within the occupation of policing in the U.S., women are vastly underrepresented. Currently female police officers' representation in police departments range from twelve percent in local police departments, around six percent in state police departments, and around eleven percent in sheriff offices (Langton, 2010). This is an increase from past decades, but it does not come close to matching the approximately forty-seven percent of women who made up the workforce in 2010 (Bureau of Labor Statistics, 2011). However, the number of women interested in starting a career in law enforcement is not the sole concern. If all interested women were hired onto police departments without question, the current environment of the police departments and the perception of police work would likely deter many other women considering policing as a profession. Problems such as sexism, harassment, double standards and paternalism cause stress, lack of job satisfaction and even resignations (Martin, 1979; Martin, 1980; Remmington, 1981; Wexler, 1985; Zimmer, 1988; Martin, 1990; Yoder, 1991; Belknap \& Shelley, 1992; Martin, 1994; Haarr, 1997a; Haarr, 1997b; Sass \& Troyer, 1999; Whetstone \& Wilson, 1999; Whetstone, 2001; Krimmel \& Gormley, 2003; Haarr, 2005; Lonsway, 2006; Archbold \& Schulz, 2008; Bochantin \& Cowan, 2008; Gustafson, 2008; Rabe-Hemp, 
2008; Wertsch, 2008; Archbold \& Hassel, 2009; Cowan \& Bochantin, 2009; Rabe-Hemp, 2009; Schulze, 2010a; Schulze, 2010b; Hassell, Archbold, \& Stichman, 2011; Haarr \&Morash, 2013; Kingshott, 2013). Historically the role of women in policing was not created on an equal footing, with women's work supplementing male police officers and keeping women out of leadership and coveted positions such as detectives (Higgens, 1950; Melchionne, 1967; Remmington, 1981; Martin, 1990; Schulz, 1993a; Schulz, 1993b; Haarr, 1997).

Many other professions have an over or underrepresentation of women including nursing, construction, and others. These professions tend to have a traditional male and female make-up that changes little year to year. This is true for the representation of ethnic or racial groups as well. Finding out why certain professions attract males or females could help bring new job candidates with different backgrounds and foster diversification. Focusing on one profession that continues to be dominated by males can provide insights that can potentially be used in analyzing other professions. This study will investigate the effectiveness of the theory of tokenism in explaining why policing has been difficult for women to gain equality in policing. First, tokenism itself must be explained.

In 1977, Rosabeth Moss Kanter outlined her theory of tokenism to explain the unique experiences of women in the business world. She defined a token group as one made up of fifteen percent or less of a workforce who face challenges that are not experienced by the majority group. The three core tenants of tokenism include the token's heightened visibility and performance pressures, contrast and isolation from the dominant group, and assimilation and role encapsulation of the token. Tokens experience greater 
visibility compared to members of a dominant group which heightens the consequences of their actions. This can lead to greater stress put upon the tokens and a decrease in job satisfaction (Belknap \& Shelley, 1992). Tokens experience role encapsulation when dominants expect tokens to fulfill stereotypical roles. Female police officers tend not to be judged as individuals comprised of unique traits but rather women embodying categories such as the "seductress" or the "mother" (Kanter 1993). This can lead to role conflict as male police officers might value the expectation of female police officers taking on a "mother" role at work, but resent their role as an actual mother at home (Cowan \& Bochantin, 2009). Finally, tokens are also at risk of being socially isolated from the dominant group, as their stark differences make the dominant group close ranks against the tokens. The strengths of the dominant group become the expectations tokens must display and dominants do their best to turn tokens against other tokens, (Martin, 1979). Using this framework, several authors have applied tokenism to their research and have found some support for the main concepts (Belknap \& Shelley, 1992; Krimmel \& Gormley, 2003; Archbold \& Schulz, 2008; Gustafson, 2008; Cowan \& Bochantin, 2009). In the field of policing, there is some evidence supporting a difference between departments with less than fifteen percent female police officers and those with more. Krimmel and Gormley (2003) found that female police officers representing less than fifteen percent of the department reported more negative feelings than female police officers at a department with more than fifteen percent female police officers. Archbold and Schulz (2008) found that another group of female police officers representing a fifteen percent token group reported they had to work harder, but that they were not socially isolated from male police officers. The study also found that female police 
officers felt they had a good chance at promotion, escaping role encapsulation, but they believed that they would be promoted not on their individual qualifications but rather their gender alone. This was seen as a negative to women, who wanted their promotions to stand on merit alone instead of a desire for more diversity. Archbold and Hassell (2009) discovered this in another police department with fifteen percent female police officers, as the female police officers believed they would be promoted due to their gender. They suggested that increasing the percentage of women above fifteen percent might not be enough to prevent differential treatment. Finally, in a rare quantitative study of tokenism in policing, Gustafson (2008) found weak to moderate association with visibility issues, weak association for isolation, and inconclusive results for role encapsulation.

Even with this evidence of tokenism in policing, it is likely impossible to study departments where male police officers make up less than fifteen percent of a department. This is important because there is evidence that male tokens do not experience the same issues as female tokens. Williams' (1992) research of men employed in predominantly female careers rode a "glass escalator" to ride to the top of an organization. Men were encouraged into applying for administrative positions, but unlike women who felt this is a negative, men took these opportunities (Williams, 2013). This points to a deeper cultural divide between men and women, instead of solely a numerical divide. In this case tokenism is still useful as a platform for more investigation and building an understanding of the reasons female police officers and other female tokens do not take advantage or cannot take advantage of their token status. 


\section{Summary}

The current body of research on tokenism is brief but compelling in its characterization of the problems female police officers face on a regular basis. The effects of tokenism on women in policing needs to be studied further to prove or disprove its ability to explain the different experiences of men and women police. Studies exist that apply tokenism to policing successfully (Krimmel \& Gormley, 2003; Archbold \& Schulz, 2008), but there are no studies that effectively focus on the validity of tokenism in policing. This study will help to further fill out the research on tokenism by exploring the experiences of current female police officers through three research questions targeting the presence and effects of being a token. Chapter II will focus on the literature related to female police officers' history in policing, the current status of women's integration into policing, and the theoretical framework of the study using the theory of tokenism. 


\section{CHAPTER II}

\section{REVIEW OF RELATED LITERATURE}

\section{General Literature Review}

To understand how being an underrepresented group within a majority male and white profession has become accepted as a normative state, it is necessary to look at the history of women in policing. Women's involvement in U.S. policing has not followed a parallel path with men in policing, nor has it often been directly related to major changes in policing. Milestones and markers advancing women's participation as police officers and administrators have often been from direct confrontation with the existing police establishment. This has led to some major changes for women interested in policing, but the true effects on the whole of policing happen at a glacial pace from the late $19^{\text {th }}$ century to the early $21^{\text {st }}$ century. Women have met resistance at every step of the way from prejudice against the physical capabilities of women, their perceived mental differences from men, procedural obstacles conflicting with pregnancy and childcare, and a historically hostile work environment. This chapter will review the literature surrounding the experiences of women in policing. The first section will review the historical experiences of women in the U.S. policing structure from the first titled policewoman to the recent effects of lawsuits on police integration. The second section will focus on the current state of women in policing including current characteristics of female police officers, obstacles facing women seeking entrance into policing and 
furthering their careers as female police officers, and finally the effects of mentoring and role models on recruiting new female police officers and successfully integrating them into the police subculture.

\section{History of Women in Policing}

The First Policewoman. In 1893, Mary Owens was the first woman hired with the police who had full arrest powers (Schulz, 1993a). Her position revolved around serving the courts and assisting detectives on cases involving women and children. Her initial appointment, however, was granted as a loophole for her receiving a pension after her husband, a policeman, died. The department hired her as a policeman instead of bothering to rename the position to a gender specific or gender neutral title such as policewoman or police officer. This emphasized her position as a mostly ceremonial title instead of opening the possibility of hiring another woman as a policewoman in the future. Even before Owens, women would sometimes run for the office of sheriff after their husband's term as sheriff had expired. It did not mean that the wife had equal authority as a sheriff, but rather allowed the husband to continue his law enforcement duties by skirting around election laws.

The Police Matron. As opposed to the empty titles bestowed to women "law enforcement officers" during the $19^{\text {th }}$ century, the police matron has had a lasting effect on women in law enforcement that can be seen in vestiges today. Assigned to work in police departments and jails in the 1800 s, these women believed they would do a much better job than men dealing with women and children (Schulz, 1993a). The view of the police matron was one of morality and the caretaking of women and children, which many progressive female women of the time considered the most vulnerable of society. 
The ideal matron was a woman of upper-middle class with a college education and a background in social work who had a strong idea for the place women should take in society. Women were to assist men by using what they considered the "natural caretaking instincts" of women combined with a desire to keep women safe from the corruptive influence of a male caretaker. Men were not challenged in any way by the area of influence the matrons set aside for themselves because it ran parallel to a patriarchal ideal of a woman as a servant of men and a caretaker of children. The police matron evolved into the first generation of policewomen, sharing the belief that a woman would be better served by keeping a separate sphere of influence from men.

The Origin of the Policewoman. As with the origin of the police matron, the original concept for the policewoman was rooted in college-educated, upper-middle class and feminist ideas. According to Schulz (1993a), Alice Wells was named the first official policewoman in the U.S. to be sworn in and gained a position through her own political action instead of a ceremonial title. Wells education was in social work and her previous work experience was in charitable and missionary work. Her background in caretaking of the underprivileged helped her form the idea that policewomen would be more educated than policemen and have a separate sphere of influence. Policewomen would focus on crime prevention, the protection of women and children, and staying isolated from male criminal exposure. Wells also spent a lot of time travelling the U.S. and eastern Canada making speeches supporting her belief that policewomen could supplement men and protect them from "delicate situations" (Schulz, 1993a). Despite Wells' success in her position, there was still resistance in women having any agency in policing, even in a sphere separate from men. Leevy (1948), an associate professor at Purdue University who 
was the co-director of the Junior Police and Police Matron's Conference in 1947, proposed that the education and knowledge for policewomen of this era should be incredibly high without women having any direct agency within policing. Instead of having actual authority or extra powers, Leevy suggested the college-educated and wellread policewoman should consult with men in matters where a women's stereotypically natural talents reside. For Leevy, women should not be a "crime detective" or "crave power," but support her male superiors in supervising women. For example, Leevy expected women to work with visiting teachers in charge of children being absent from school, but not to replace the teacher by punishing students and women should help in juvenile courts, but should not be a prosecutor or defender. In all things he proposed, Leevy wanted police matrons to give up active participation and consult with those men already within the criminal justice system.

The idea that women should not be actors within policing was disputed by Higgens in 1950. Higgens accepted that policewomen should have their own specialization rooted in social work and focusing on rehabilitation instead of duplicating the duties of male officers. These policewomen would focus on helping the individual and not in just upholding the law. To do this, Higgens suggested the key difference between policemen and policewomen should be that policemen must act while policewomen may act. Within this debate, the first generation of policewomen emerged without the full authority of patrol officers but more authority than women in lawenforcement before them. As with the police matron, these women believed that a policewomen's "unique resources" should focus on protecting women and children from exploitation. At this time, the 1950 s census reported there was 2,610 policewomen that 
accounted for around one percent of all police (Melchionne, 1967; Schulz, 1993a). This started a very incremental change that continued to gain momentum through World War II.

Changes after WWII. The numbers of policewomen started to increase through the 1950 s as "moral concerns" accompanied the return of men from the war. The primary moral concern was to prevent women's exploitation from the returning men, in the tradition of women's place as their sister's keeper (Schulz, 1993b). Unlike the first generation of policewomen, the new generation of women entering the police force had a very different background and motivation for entering policing. Instead of collegeeducated and upper-middle class women seeking to help prevent the moral degradation of other women, these new women usually only had limited college educations and came from a working or middle class background. Also, unlike the policewomen of the past, the new policewomen were seeking a civil-service career with promotional opportunities. These women saw being a police officer in much the same way as a male police officer did, as an evolving career instead of a stagnant job. According to Schulz (1993b), the 1960 census reported 5,617 policewomen, which was round two percent of nationwide police force. Lawsuits were a very effective method women used to help gain a foothold within policing.

Even before the Equal Employment Opportunity Commission was empowered to enforce existing laws under an amended Title VII of the 1964 Civil Rights Act, policewomen used the courts to open new opportunities for themselves. New York policewomen Felicia Shpritzer and Gertrude Schimmel sued the New York City Police Department as they were barred from taking the exam due to their gender. Policewomen 
such as Betty Blankenship and Elizabeth Coffal were now seeking out opportunities to enter more prestigious positions such as patrol and investigations as well as entrance into true supervisory and administrative positions (Schulz, 1993a; Schulz, 1993b). While over fifty years has passed, there is still discrimination women face in gaining access to the same opportunities that these women sought through lawsuits in the 1960s. Despite the existence of the same discrimination today, these examples of lawsuits before and those after the empowerment of the EEOC had a significant impact on the number of women being hired as female police officers. In an analysis of the factors that led to police departments having a larger percentage of women, anti-discrimination lawsuits had a positive effect on the number of female police officers hired. Anti-discrimination lawsuits before 1981 helped promote hiring new female police officers from the early to mid1980s (Sass \& Troyer, 1999). The percentage of female police officers was around seven percent in 1981 and increased to almost nine percent in 1987 while departments with no female police officers decreased from eleven percent in 1981 to seven percent in 1987 (Sass \& Troyer, 1999, p. 66). This trend has continued, and the current percentage of women in policing has continued to increase since the late 1980s.

Current State of Women in Policing. The percentage of female police officers today in the country is still increasing and according to the Bureau of Justice Statistics in 2007 women accounted for eighteen percent of the sworn officers in departments with 2,000 or more personnel with Detroit in the lead with female police officers accounting for twenty-seven percent of their police department (Langton, 2010, p. 3). From 1987 to 2007 female police officers in local police departments increased from near eight percent to twelve percent and female state police officers increased from near four percent to 
around six percent (Langton, 2010, p. 3). However, female police officers that have full law enforcement functions in sheriff offices declined from near seventeen percent in 1997 to around eleven percent in 2007 (Langton, 2010). As shown from these statistics, there are specific characteristics to departments that hire women.

\section{What Departments Hire Women}

Size of Department. As shown by the Bureau of Justice Statistics in 2007, larger, urban departments and local police departments have shown a rise in the percentage of female police officers (2010). There is statistical evidence to suggest that the larger the number of police department personnel, the higher percentage of female police officers hired by the department (Sass \& Troyer, 1999). Despite increases in other areas, rural departments displayed around a four percent decrease in female police officers in from 1997 to 2007. The Bureau of Justice Statistics suggested this might be due to only including female officers that have full law enforcement powers (2010). This is an interesting side note as it suggests that past percentages of rural female officers might have been overrepresented. An officer without full law enforcement powers is very similar to the first generation of policewomen, and might not be considered to be a full police officer.

Percentage of Women at a Police Department. Another important factor in determining how likely a females will be hired is the existing gender composition of a department. Sass and Troyer (1999) discovered that male dominated departments are more likely to have fitness tests that are a barrier to hiring new female police officers, and prevent female police officers from gaining a larger presence to change hiring practices. A department with a higher female representation has found ways to integrate females 
better into the hiring and training procedures that help integrate women into police departments. These departments also are more likely to have female police officers in supervisory and leadership positions which give female recruits an example of the possibilities of working in that department. Having an existing female police officer pool is positively correlated with hiring more female recruits, but it is not a snowball effect. The rate in which women are hired into police departments is still increasing very slowly and even in urban departments women are nowhere near being equal to men. This might be due to women not applying for policing jobs as frequently as men, but that too is a point that needs to be addressed. Policing jobs are well-paying positions and there is nothing to suggest that women would value being a police officer any less than men, nor is there anything to suggest that they would do a worse job at being police officers. Having female role models already working as police could increase the rate at which women apply for police jobs, and therefore more rapidly increase female representation in policing. More female police officers can also help hasten change in the bureaucratic and social order barriers which make it more difficult to keep female police officers from leaving and help them stay motivated to help their departments.

\section{Integration and Socialization into Policing}

Barriers to Hiring. According to Melchionne (1967), barriers to hiring women included views that: Policing was a man's job, women have less strength and endurance, women had family responsibilities and got pregnant, women were emotional and high strung, and policing did not fit women's proper status. These traditional expectations still persist and promote the ideal of the tough-as-nails male street cop as the only way to deal with criminals and citizens alike. Women infringing on this stereotype are treated as 
trespassers by male police officers who expect female police officers to prove themselves repeatedly within this context. These exaggerated barriers have been created to keep women from being hired, integrating into the police subculture, balancing work life with family life, and being promoted or gaining prestigious positions.

Physical Fitness Tests. The current physical fitness tests for new hires into policing have been shown to not only be a barrier to hiring females, but also do not accurately test the physical standards that a police officer encounters on a daily basis. The popular view of a police officer's work is one of conflict, both mentally and physically on a day to day basis where physical fitness is tantamount. Opposed to this, Sass and Troyer discovered the job of a police officer involves mostly sedentary activity and involves patience, paperwork and social contact (1999). Physical fitness is a key factor in dangerous situations, but having every police officer aspire to the physical minority instead of the social majority of police work misses the reality of policing. Another often discussed topic is that most departments only require physical exams for new hires and do not follow up by testing experienced officers. This has been hypothesized as a direct, and intentional, barrier to hiring female police officers by departments with a predominantly male composition or union presence (Sass \& Troyer, 1999). The idea behind this hypothesis is that unions and male-dominated departments seek to keep control of the mainly male composition of the department protected through physical exams that preference physical tests that males excel at over women. By not retesting officers after the hiring period, the physical fitness aspect of being a police officer loses its importance after its initial effect as male dominated gatekeeper. Related to this, female police officers are more likely to report their abilities were questioned due to their 
physical qualities despite being able to pass the same physical entrance exams males are required to do (Hassell, Archbold \& Stichman, 2011). This becomes even more difficult if a female police officer is married to a male police officer.

"Marriage Tax." Shift work is an integral part of being a police officer since most departments want to keep officers on the streets twenty-four hours a day. Working during periods when many other people are off of work or sleeping can make it very difficult for police officers, both male and female, to have what is considered a normal social life by non-officers. This can be especially difficult for many female police officers who not only work shift work but are entrenched in the traditional belief that women should be the main caretakers for children while men work. Unless the woman is in a relationship to another person working the same schedule that they are, this also means that they will either have to miss out on sleep or not see their significant other. Women are also expected to take care of children in most cases, daycare and on-call childcare need to be secured so female police officers can work at a moment's notice. This causes strain on relationships and families, causing more stress for the officer on and off the job (Archbold \& Hassell, 2009).

Work and life conflict is the same for male police officers and female police officers, and relationships within police departments are not uncommon. Some research even suggested that females who did not marry or have a relationship with a male police officer were kept outside of the social circle of male police officers. Not only did this separate the female police officer from participating in different social events but could also affect support on and off the job (Bochantin \& Cowan, 2008). Being married to a male police officer will shield a female police officer from some of these effects, it also 
exposes them to what Archbold and Hassell (2009) call the "marriage tax." The marriage tax suggests that the appearance of nepotism in a married heterosexual relationship will prevent the advancement of one of the partners. As such, the husband more likely to be promoted as they tend to enter the workforce younger than women (if married) and antinepotism policies punish the wives who seek promotion (Archbold \& Hassell, 2009). Marriage this could be an avenue for getting women hired into police departments as the husbands might use their influence to get them hired, it would be a limited path that would make give the appearance to potential female recruits that single women not affiliated with the police department will not be selected or will eventually have to marry a male police officer to stay within the department. Either way, it is an unacceptable trend that punishes women unfairly both for being married to an officer and also for not being married. The marriage tax will likely get more widespread as females enter the police force in greater numbers and more time is spent at work and socializing mostly with coworkers (Archbold \& Hassell, 2009). Combating nepotism within civil service positions is a valid concern to prevent family control over government positions, but it needs to be balanced with a fairness that takes into consideration the benefits of a diverse mindset. Another challenge the male police officer does not face in a marriage with a female police officer is pregnancy.

Pregnancy and Light-Duty Assignment. A uniquely female experience that truly separates women from men is pregnancy. An involved spouse can able to help as much as possible by supporting the pregnant woman and newborn child, but a women alone experiences the physical and emotional changes of being pregnant. Also, Schulze (2010a) found that many female police officers perceived inequality in marriages which could 
force female police officers to take more leave due to childcare as they receive less support at home. Many women keep very active up until their due date, but the manner in which a police department helps or hinders a female police officer determines how well an officer can do their job before and after giving birth. The Family Medical Leave Act (FMLA) and light-duty policies are a direct response to disabilities of which pregnancy is included (whether or not calling pregnancy a disability is insulting to some). According to FMLA, an employer must make efforts to determine if a position is available that a disabled officer can perform, if they cannot be accommodated in their current position. Accommodating a pregnant officer in light-duty assignment and appropriate maternity leave helps to increase officer safety, encourages officer retention, and alleviates the financial concerns of female police officers. Having a policy in place can also help to alleviate the financial concerns of police departments as well as there has been a sizable increase in the amount of pregnancy discrimination lawsuits in the U.S. (Rabe-Hemp, 2011). Despite this, many female police officers are not made aware of their department's FMLA policies and much like the decentralized policing system in the U.S., FMLA policies are vastly different from department to department (Schulze, 2010b). Making officers aware of their FMLA policies during their initial training period and having updates as needed will not only benefit women but also men in police departments. Decreasing the chance of re-injury will prevent premature resignation due to injuries and younger officers who are injured or unable to work tend to want to return to work much sooner than older officers (Rabe-Hemp, 2011). Hiring, training and socializing officers successfully into policing takes much more time and resources than preventative care in making sure officers have time to heal and recover from life events such as pregnancy. 
Along with helping female police officer reintegrate after pregnancy, ways of finding out how to help increase the number of female police officers in supervisory positions benefits every female police officer.

Unsuccessful Integration and Voluntary Resignation. Women are not only affected by workplace stress, but also factors unique to being a woman, an underrepresented group ethnicity, or both (Haarr, 2005). As civil servants, police departments and their officers operate within the vast and endlessly complex patchwork of government bureaucracy. Officers must carefully balance the rules, regulations, and laws with the discretion they have available to them in enforcing safety and security. In an ideal world this would not cause any conflict as officers would be able to equally treat everyone within the umbrella and laws and regulations. In the waking world, equal enforcement causes many issues as it removes the ability of officers to avoid enforcement by educating people on what not to do in the future and allowing them to avoid the costly and lasting effects of the court system. This conflict of the ideal and real world causes most officers to engage in some form of deviance to match their views of what an officer should do. This can take the form of a highly dedicated officer breaking the rules to arrest someone they believe is guilty or a less dedicated officer avoiding work as they don't believe their job is worthwhile (Haarr, 1997b). In addition, through interviews with police officers, researcher Robin Haarr discovered that on-duty male officers would engage in sexual misconduct and some were even accused of rape by fellow officers. In addition, one female police officer reported that she had followed male police officers into strip bars and acted as a lookout while male police officers had engaged in sexual activities with strippers and prostitutes on-duty. The lack of respect shown by the male 
police officers towards women and female police officers by treating their position as a way to illicit sexual favors is a significant barrier for female police officers seeking to integrate into police society. The single female police officer faces increased stress based on their gender that includes gossip, training bias, lack of promotions, and a double standard where women are expected to prove themselves repeatedly (Lonsway, 2006). Being married to male police officers appears to shield female police officers from harassment and discrimination in hiring, training and their career that single female police officers face on a daily basis (Lonsway, 2006). This helps to reinforce the idea that female police officers need to buy in to the male dominance of policing and submit to traditional stereotypes of women or face isolation and discrimination.

FTOs use a military-style training model to degrade recruits "by breaking them down and building them back up" that creates a "conflict and cognitive dissonance" in many recruits that seek to join the police in order to help people instead of just punishing them (Haarr, 2005, p.94). Throughout the training process from the academy to field training, the perpetuation of the ideal police officer is upheld as the tough, macho cop and women are held back as outsiders (Haarr, 2005; Lonsway, 2006; Rabe-Hemp, 2008).This is exacerbated in female and/or recruits of other underrepresented groups that also experience sexual and racial harassment from their initial police training, to their experiences with FTOs, their probationary period, and much of their career after (Bochantin \& Cowan, 2008; Haarr, 2005; Kingshott, 2013). Female police officers face a constant balancing act between their perception of themselves and their male coworkers' expectations of what they should be. 
Fitting into the Male Expectations of a Female Officer. Being repeatedly exposed to an environment that is openly opposed to their presence and based on an expectation of buy in to hegemonic masculine values means that women who seek to integrate fully into policing must appease this environment by fitting themselves into an expected role created for them (the tough cop). Those who rebel against their expected roles and still endure as police tend to highlight their differences and face isolation, but they have a better chance at promotions and forcing respect through rank (Rabe-Hemp, 2008; RabeHemp, 2009). This is not to say that there is only a divide between men and women alone, but also intersections of gender and race. Martin (1994) in her analysis of the experiences of both white and African-American female police officers found that while all women shared some sort of bias or bigotry from male police officers (both white and African-Americans), that women also were divided against themselves. Whether this divide was caused by racial bias, the threat of isolation from male police officers, or other differences, it made cooperation for gains for all women difficult to accomplish. Historically, there are examples of African-American women disagreeing with white women over who should be included as a "minority" in need of assistance. AfricanAmerican women reported resenting the inclusion of white women into the same category because they believed it resulted in less African-American women and women of other underrepresented groups being hired as a result. It could be argued that having two categories of "minority" and white women could have increased the hiring of both categories in an effort to fight discrimination, instead of just a small increase in the hiring of women in general. The strongest effect of combining women and other underrepresented groups together was to reinforce a divide and conquer strategy Martin 
(1994) found men used to separate women of all races from working together. Effective mentoring and leadership could avert this strategy, but there is little research of the topic and therefore not many effective plans in place to increase the number of mentors and mentees.

Mentoring and a Lack of Role Models. As women make up a very small percentage of the police nationwide, it logically follows that there is also a lack of role models for women to follow into policing. A female police officer is likely to see mostly males in the supervisory and leadership roles, as well as the more prestigious specialties such as SWAT teams and investigations. This could have a strong impact on women who are not only seeking to enter policing as a career, but also the women who are already police officers evaluating their chances of moving up the ranks in supervisory or specialty positions. Increasing the numbers of female police officers in general can help to expand the perception amongst women that they can succeed in policing. Another popular tactic to reach out to women and motivate female police officers is the female mentor. Hassell, Archbold and Stichman (2011) found that female police officers were more likely to believe and mentoring program was needed. They also proposed that mentoring helps to establish support networks among officers which can help to reduce officer stress which, in turn, leads to officer retention. Mentoring can be an important method for changing female police officers and female recruits' perceptions of a career in policing. As well as how men treat women within policing, mentoring can help to combine the best characteristics of both genders. In the existing police culture, there are strategies that can support female police officers to advance in rank and gain more influence in policing. 
Ways to Assist Female Promotion. Past research has suggested several options to help ease the burden of female police officers seeking promotion (Archbold \& Hassell 2009). The first suggestion was for police departments to offer affordable on-site daycare for officers, allowing them to avoid having to schedule on-call babysitting and pay extra for off-hours daycare. Not only could women benefit from this but also men who are the primary care providers for their children or who are married to other officers on the job. However, in a male dominated culture with very ingrained beliefs about who should be a child's primary caregiver, providing on-site daycare that the department pays for could also be seen as giving preference to female police officers even if male police officers would also benefit. This could also be very expensive for departments, especially small to medium departments, as it would require shifts of daycare workers and indoor and outside space to be available at all times. The costs could be alleviated by sharing facilities with other shift work civil service positions and could share in its costs. Despite the benefits, having the service on-site would be very difficult to accomplish as departments would have to be subjected to expensive retrofitting and there could be legitimate safety concerns from officers who do not want their children near a police department. This concern for safety could also be extended to daycare facilities dedicated to police officers as many officers do not want their children to be singled out as children of police officers. It would be impossible to keep such a facility hidden from most people who wanted to find it in the age of easy access to most information, which could lead many protective parents to still prefer private daycare. Future research would need to evaluate the interest of officers in this idea and whether it could be realistically implemented. 
Predictable and flexible schedules. Being provided with exactly what hours a supervisor works can help officers plan if a promotion will work for them. Flexible schedules is another way to help gain more candidates for promotion because it helps officers fit being promoted into their lives. These suggestions would be very difficult to implement, as being a police officer means they are mandated to report and work as long as they are needed. If there is no one else who can relieve an officer, which is very likely to happen to supervisors that are few in number, then that officer needs to stay on duty. This could be avoided by having enough supervisors who work non-traditional shifts and provide coverage for any contingency, but that is a large financial burden for many small to medium sized departments. The complexity of flexible schedules would also be a large hurdle to overcome as traditional scheduling and shift preference tends to be based on seniority and can change month to month or year to year. Also, this could increase the perception of preferential treatment for line officers and degrade the working relationships between officers and their supervisors.

Increase in supervisor pay. Increasing supervisor pay can make promotion more attractive to many officers. This could be a standard increase in pay or allowing overtime for supervisors, which some departments already do. This is a large financial burden for departments to shoulder but, if departments have exhausted all other avenues to improve the attractiveness of being a supervisor, it could be considered. Also, there is a dissonance within many police officers between the reality and perception of a supervisor's pay. In many departments officers need to work many hour of overtime to make more than a supervisor and supervisors have access to nearly as many on and offduty job opportunities as line officers (Whetstone, 2001). Catering too much to the 
concerns of female police officers without helping male police officers singles out female police officers and hinders female police officers seeking promotion.

Stop actively recruiting female police officers for promotion. As previous research as discovered, many white female police officers resisted the promotional process because they were actively recruited by supervisors to apply (Archbold \& Hassell, 2009; Archbold \& Schulz, 2008; Whetstone, 2001). The researchers found that female police officers saw this as a sign that they would receive the promotion not because they were qualified but rather because they were female. Many female police officers suggested they needed more years of experience and time on patrol before they would even consider testing for promotion. The researchers came to the conclusion that it would be more helpful for supervisors to stop actively asking female police officers to apply for promotion, even if the departments were aggressively seeking diversity within their supervisors. They concluded that this would help female police officers feel less singled out compared to male police officers and improve the perception that a female police officer promoted to a supervisory position earned it through merit and not due to their gender. This could put departments at risk, however, as it could make them appear to not support diversity in their leadership. Public perception is a major part of a civil service position, and if a department can show proof that it is seeking out qualified female police officers to participate in the promotional process it will have a better public image for many civilians than those departments that are not proactive in their approach. Waiting for an increase in the percentage of women who become female police officers and hoping they will naturally seek out promotion in the current police culture has not achieved much integration. African-American female police officers did not share the 
same beliefs as their white counterparts, as they felt their visibility as an AfricanAmerican female police officer make them a positive role model for other AfricanAmericans in their community (Whetstone, 2001). Instead of focusing on their visibility to other officers they believed being present as a positive role model for AfricanAmerican communities would only benefit youth and young adults.

There are also many factors that male police officers and female police officers share in avoiding the promotional process (Whetstone \& Wilson, 1999). The main difference between men and women was the perception among women that they would face administrative bias after being promoted. According to the research this bias and discrimination was reported primarily by African American officers, pointing out an undercurrent of racism inherent in a traditionally white and male dominated profession. This puts administrators into a very difficult situation, as they must balance the research that suggests women report being singled out when they are asked to participate in the promotional process and the perception that they will not be treated fairly when promoted. As suggested by Martin's (1994) research into the intersections and divergence of race and gender on being a police officer, a one size fits all approach in encouraging women to seek promotion could be shortsighted. Research using a larger sample of women conducted in modern policing could elaborate on how detrimental racism is in discouraging non-white women to seek a career in law enforcement. If white women are disproportionately being asked to participate in the promotional process over African American women, then giving up on asking women to seek promotion is flawed. Administrators can seek out qualified, African American women for promotion and help to increase the proportion of African American female supervisors as they do not turn 
away from being asked to participate in the promotional process. This could also provide a larger pool of role models or mentors for female police officers, limiting the need for administrators to actively ask female police officers to apply for promotion. The downside of such an approach could increase the male police officer perception that females are promoted only because they are female, increasing officer deviance and work avoidance (Haarr, 1997b). Some research has suggested the older, more overtly sexist and racist officers are dwindling in number, but there is not targeted research on this topic (Rabe-Hemp, 2008). Next the theoretical framework for this study will be discussed.

\section{Theoretical Framework}

Female police officers are affected by issues such as the traditional views of policing, hiring practices emphasizing physical strength, a lack of women in departments to act as role models, and a reluctance of female police officers to band together to help one another. At the center of these issues is the female police officer's status as a token surrounded by the dominants consisting of white male police officers. Kanter (1993) put forth a version of a theory of tokenism in 1977 that has been used in the law enforcement world (and others) in order to explain the differences that tokens and dominants experience in their careers. A token is part of a skewed group dynamic where eighty-five percent or more of the group consists of dominants who share similar broad characteristics, such as white males. The token group makes up the other fifteen percent of the group and does not even qualify as a minority, as minority groups have more allies to work together for some measure of change (Kanter, 1993). Kanter's 1977 examination of women in a large company outlined different pressures that tokens consistently faced at work. They describe how the dominant group creates different expectations of success 
for a token, keeps tokens isolated from the dominant group and other tokens, and enforces roles based on existing stereotypes instead of individual characteristics. The three constructs she discovered from token women's experiences included visibility/performance pressure, contrast/isolation, and assimilation/role encapsulation.

Three Pillars of Tokenism. First, visibility creates performance pressure for tokens as their fewer numbers make them stand out more than the majority. They must work harder to be recognized for their actions and their mistakes are not only heightened but also affect other minorities belonging to the same group. If a token does better than the majority and "shows them up," they must fear reprisals from dominants threatened by their success. In policing this could mean a longer wait time for male back-up and a general hostile attitude towards all women in a department if one female police officer makes a mistake. Belknap and Shelley's (1992) findings included that stress for female police officers increased from gender-specific issues such as the need to prove themselves constantly, alongside sexism and negative views of women whereas job satisfaction increased alongside the number of female police officers at a department.

Second, contrast between the token and the dominants leads dominants to heighten cultural boundaries, isolating the token. The token, as a perceived outsider, makes dominants feel uncomfortable and close ranks against the tokens. Female police officers are not allowed into the "folds of the department" after male police officers close ranks, and tend not to have informal bonds with male police officers (Haarr, 1997a). Dominants also create barriers against tokens entering their profession such as physical agility tests (Sass \& Troyer, 1999). The best characteristics of the dominant group become the comparison that tokens must aspire to, and dominants pressure tokens to turn 
against other tokens that do not meet these expectations (Martin, 1979). This could also be reflected in female police officers being kept out of social events after work or networking within police organizations (Haarr, 1997a; Rabe-Hemp, 2008). Female police officers are also not consistently accommodated consistently for maternity leave, with a patchwork of different policies from department to department (Schulze, 2010). This leaves many women to fend for themselves to figure out their own department's policy instead of the department making its policy known to everyone (male police officers and female police officers) at the time of hiring.

Finally, assimilation results in token role encapsulation that promotes stereotypes which tokens are expected to follow. Dominants have stereotypical expectations of what role a token should play and what skills they should be good at. Female police officers can focus on being women first, and being stereotyped as weak and unworthy of "real police work," or police first, and being stereotyped as a "bitch" or "lesbian" (Martin, 1979). Martin's (1979) study on tokenism divided female police officers into policewomen and policewomen where the emphasis describes how a female police officer navigates their token status. Using interviews and observations collected from a previous study on female police officer integration into police patrol at the time, Martin divided women into "defeminized" and "deprofessionalized" categories of policewomen and policewomen (1979, p. 134). For both male police officers and female police officers, women were both expected to show no signs of weakness and yet portray a traditionally feminine stereotype. Women who focused on their careers isolated themselves from other women to gain support from the male majority (Wertsch, 2008). Women who emphasize their femininity were more likely to attempt to be more vocal in seeking a coalition 
between women but were little respected by men and other career-oriented women (Martin, 1979). Rabe-Hemp's 2009 study found women rejected classifying themselves in either category, but ten years later the stereotypes still persist.

Evaluations of Tokenism. There are few studies that measure the statistical significance of Kanter's fifteen percent qualifications of a token group in policing. The findings of these studies are inconsistent on the validity of tokenism and no study focuses strictly on the evaluation of the three core constructs of tokenism. Krimmel and Gormley's (2003) study looked at a sample of 300 Pittsburg, Pennsylvania and state of New Jersey female police officers at the Women in Law Enforcement Conference and at the Criminal Justice Center in the state of New Jersey. Their survey results found that female police officers that made up less than fifteen percent of a police department reporting negative feelings towards being a police officer, including not recommending a career in law enforcement to others, than those in a department with more female police officers. This study, as most studies on tokenism, lacked randomization and reliability due to using a purposive sample (Krimmel \& Gormley, 2003) Archbold and Schulz (2008) conducted a study at a Midwestern municipal police agency in a city of around 100,000 people. The POs in the agency were almost completely white and male, with only fifteen percent being female police officers. Archbold and Schulz (2008) found that female police officers in their sample did report that they had to work harder than male police officers, they did not report being socially isolated, and while they did report their chances for promotion were good, they believed they would be promoted solely due to their gender, not aptitude. Gustafson's (2008) multivariate analysis of data collected from another study on Baltimore police officers analyzed the three pillars of tokenism. His 
purpose was to further the small body of statistical evidence for or against tokenism. He a found weak to moderate association with visibility and performance issues, weak association for contrast and isolation, and an inconclusive association for assimilation and role encapsulation.

An important criticism of tokenism is the gender neutral approach of Kanter's tokenism that focuses solely on numerical proportions instead of societal gender discrimination (Yoder, 1991; Zimmer, 1988). Heterosexual white men experience a "glass escalator" that advances their careers instead of hindering them (Williams, 1992; Williams, 2013). In her research, Williams discovered that men in jobs that were traditionally considered female had a vastly different experience than women seeking jobs in fields that were traditionally considered male. The four professions targeted were nurses, elementary school teachers, librarians and social workers. Heterosexual white men were pushed towards higher paying careers within these professions, which men accepted (Williams, 1992; Williams, 2013). As discussed earlier, police administrators also pushed female police officers to apply for supervisory positions, which many women identified as a deterrent for seeking out promotion. The negative stereotypes male tokens do seem to experience are often felt off the job instead of on it. They were sometimes considered "odd" or homosexual, both of which were portrayed as negative attributes (Zimmer, 1988; Williams, 1992).

\section{Summary}

The slow trek towards equality within policing for women is far from finished and there are many barriers that female police officers still face. As mentioned, the same barriers that faced women before the inclusion of policewomen still exist: sexual 
harassment, physical expectations and the expected role of women in society. While women make up slightly more than half of the general population, in policing they are still tokens. As tokens female police officers face higher barriers and heightened visibility as their failures, as seen by the majority, extend to all within a token group and they must constantly prove themselves. Realizing that female tokens experience barriers that go past simply a fifteen percent representation in policing, a gendered view of tokenism is a valuable approach to researching female police officers experiences in their careers. Increasing numbers alone is not an effective method of reducing barriers, both selfimposed and majority-placed. Strategies such as increasing female police officer networking opportunities, making promotions more appealing to female police officers, and promoting the benefits of having female police officers in a department could help if they take hold with female police officers and male police officers alike. Next, chapter III will discuss the research design including the study design, constructs of tokenism, the type of analysis used, and the detailed research questions. 


\section{CHAPTER III \\ RESEARCH DESIGN \\ Purpose}

This study advances the body of token research through secondary analysis of interview data and produce a detailed narrative of female police officer's experiences as a token. The narratives are compared to Kanter's (1977) constructs of visibility, contrast, and assimilation to evaluate the theory of tokenism's effectiveness in explaining the experiences of female police officers in policing. The small body of token research suggests that female police officers find themselves in a distinct group separate from the dominant male police officer population and without a strong female police officer subculture to depend on for support. This study asks three research questions about female police officers' experiences with tokenism corresponding with Kanter's (1977) constructs of visibility/performance pressure, contrast/isolation, and assimilation/role encapsulation.

\section{Study Design}

The data used for this research were gathered from surveys collected by Illinois State University Professor Dr. Cara Rabe-Hemp used in two previous studies (RabeHemp, 2008; Rabe-Hemp, 2009). The population of interest for this study is female police officers from rural, municipal, university, and state police departments. The sample itself consists of 38 female police officers who were mostly White with only 3 
African American officers. The sample also had a very established group of female police officers ranging from 1 to 30 years of experience with 12 female police officers being administrators. The most senior officer was hired in 1978 and the most junior officer has about 1 year of experience. Of the administrators, there was 1 chief, 1 colonel, 4 captains/commanders, 2 lieutenants, 3 sergeants, and 1 corporal. Of the line officers, 6 were detectives and 20 female police officers were patrol officers. The size of the departments ranged from 16 female police officers being in a department of more than 100 sworn members, 13 being in departments with between 50 to 100 members, and 9 female police officers serving in a department of less than 50 sworn members. Finally, the sample included 20 municipal, 4 county, 7 campus, and 7 state police officers (RabeHemp, 2009). Dr. Rabe-Hemp collected these interviews through a snowball sampling process using references from the initial contacts and following their suggestions for other officers to interview. The interviews were collected for several years and on average took about eight hours to transcribe (Rabe-Hemp, 2009).

\section{Constructs}

Visibility and Performance Pressure. A token population's small numbers make every individual token stand out due to the stark contrast from the majority. Tokens are seen by majority as a collective instead of individuals where any one token's actions are then attributed to the group as a whole. A token that makes a mistake or acts in a way contrary to how the dominant group believes is appropriate can damage the token group's reputation as much as the individual making the mistake (Harrington, 2002). This is especially true for female police officers that are hired onto smaller departments as the first woman as their every action will be used to judge if hiring more women will be a 
benefit or disadvantage (Harrington, 2002). Due to this group identity, individual tokens must work to prove themselves constantly and avoid being negatively stereotyped by their group identity (Kanter, 1993; Haarr, 2005). Morash and Haarr (2012) found that female police officers actively resisted attempts to highlight these negative stereotypes and attribute them to all female police officers at a police department. In doing so they attempted to minimize the perceived inadequacies of female police officers and highlight the negatives of male police officer stereotypes.

Lonsway (2006) found that female police officers believed there was a doublestandard where they had to continually prove themselves or work twice as hard as male police officers to be seen as equal. These double-standards also punished female police officers for having the same qualities valued in men, such as ambition, were seen as "pushy" and negative (Martin, 1990). Lonsway (2006) also found that most of the male police officers and some of the female police officers felt that female police officers were promoted or given special assignments too early in order to make a quota, get them off of line duty, or for political reasons. These officers felt the promoted female police officers would be underprepared and fail, causing damage to their reputations as well as all other female police officers (Lonsway, 2006). The female police officers that are promoted to supervisors are even more highly visible than line officers, are often excluded from informal networks essential for their success and, despite their rank, tend to be challenged by male subordinates more often than male supervisors (Martin, 1990). Some female police officer supervisors used their positions and increased visibility to end racial, sexual or other inappropriate comments but they did not change the underlying police culture therefore only had a temporary effect (Haarr \& Morash, 2013). These factors can lead to 
female police officers feeling increased pressure to work harder than male police officers and repeatedly demonstrate their abilities (Martin, 1990; Archbold \& Schulz, 2008; Haarr \& Morash, 2013) and increased stress on the job (Belknap \& Shelley, 1992). At the intersection of race and gender, Whetstone (2001) found that white female police officers reported increased visibility and promotional opportunities due to their gender was a negative. African-American female police officers reported that having heightened visibility was a good way to set a positive example in African-American communities, especially amongst children and juveniles.

Contrast and Social Isolation. Differences between the dominant group and tokens leave tokens isolated from the dominants and sometimes other tokens. Tokens do not have the same informal bonds between them that the members of the dominant groups do, leading to less support on and off the job. The lack of social integration begins in their training periods as they can experience harassment or discrimination from their field training officers (FTOs), who are a gateway for recruits gaining entry into the police culture (Haarr, 2005). Barriers such as physical agility tests and training biases are in place favoring the dominant group and female police officers that do not perform exceptionally or make mistakes are shunned by male police officers and female police officers alike (Sass \& Troyer, 1999; Lonsway, 2006).

Female police officers also form barriers among themselves by accepting, rejecting or seeking to be exempted from the standard of being a PO. In training, women must decide how to approach the physical challenges by meeting or exceeding male standards, or by seeking exemption or protection from training standards (Martin, 1980). Wexler (1985) found that female police officers could be categorized in four styles of 
being a PO including neutral-impersonal, mixed, semimasculine, or feminine. Neutralimpersonal female police officers attempted to be as effective a PO as they could be, including using their "femaleness" to enhance their policing, but this often lead them to be segregated from the police culture. Mixed-style female police officers often viewed male police officer behavior as childish instead of harmful, and often gained access to the police culture. Semimasculine female police officers thought themselves part of the traditional police group, but were often treated as "junior partners" even though they did not see themselves as such. Finally, feminine female police officers emphasized their sexuality and as such were treated as women instead of POs (Wexler, 1985).

Another way female police officers form divisions amongst themselves is by creating the "other" female persona. The "other" female police officers were personified in negative stereotypes of women ranging from being too masculine or feminine, or belonging to an undesirable group. Female police officers used the negatives of being an "other" to more closely align themselves the current dominant police culture (RabeHemp, 2009). Harrington (2002) identified groups of "other women" in policing in the context of which female police officers were positive influences and others who should be avoided. The two groups to be avoided were women who isolated themselves by wanting to be the center of male attention (the "Queen Bee") or those how wanted to be left alone outside instead of being a positive role model for other women (the "Disappearing Ghost") (Harrington, 2002). Despite the support gained from female police officers displaying positive attitudes such as the "Role Model" or Mentor" (Harrington, 2002), female police officers that choose to socialize with other women were further isolated from the dominant police culture, being referred to as the "Estrogen 
Mafia" (Rabe-Hemp, 2007). These women are viewed with suspicion from the male dominant culture, creating a punishment for female police officers seeking other female police officer support. The needs of female police officers are not accommodated as they are special exceptions instead of the part of the dominant experience, such as motherhood (Schulze, 2010). These experiences make token female police officers uncomfortable within the organization and that the male police officers close ranks against them.

Assimilation and Role Encapsulation. Assimilation and role encapsulation consists of any behavior that a token is expected to follow based on the stereotype the dominants hold for all tokens of that group. Assimilation does not take into account the token's skills, nor their personality, and the token is punished for not fitting into the stereotypes. Role encapsulation is often reinforced though assignment of jobs by sex and paternalism form administrators and other male police officers (Martin, 1980;

Remmington, 1981; Martin, 1990). Often female police officers are given assignments where they are "protected" from danger (Martin, 1980; Martin, 1990), given less prestigious jobs, or assigned to "dead-end" jobs at the police department (Haarr, 1997a). This paternalism creates a cycle that denies female police officers valuable patrol experience that can lead to worse "street" performance, stigmatizing them as inferior, reinforcing resentment among male police officers and leads to more justification for removing them from "dangerous" positions (Martin, 1990). Paternalism is reinforced through teasing, sexual innuendo and "unexpected touches" used to assert power and keep female police officers in a lower status than male police officers (Martin, 1980; Remmington, 1981). Dating or being married to a male police officer protected female 
police officers from some of this treatment, but at the cost of labelling the female police officer as a "wife" first, instead of a PO (Martin, 1980; Lonsway, 2006).

Female police officers used the popularity of community oriented policing (COP) to show that beneficial female stereotypes of being a caretaker, having empathy and using verbal skills over aggression were important in being an effective police officer (Morash \& Haarr, 2012; Rabe-Hemp, 2009). Female police officers recognized that this could be a threat to their careers by not taking on a traditional view of policing, but believed it minimized the perceived negatives of being a woman (Morash \& Harr, 2012). Despite the benefits, the unintentional effect of this could result in the further encapsulation of female police officer for generations to come (Rabe-Hemp, 2009). Rabe-Hemp's (2009) research uncovered a role conflict within some female police officers as they struggled balancing proving themselves through physical force and accomplishments with maintaining a feminine persona which would be more socially acceptable. While many modern female police officers have found success in redefining policing and gender using COP (RabeHemp, 2009; Morash \& Haarr, 2012), the ongoing struggle for female police officers has been when to "act like a cop" and when to "act like a woman" (Martin, 1980; Wexler, 1985; Martin 1990). This struggle if often reinforced through assignments according to sex, treating women paternalistically, and sexualizing female police officers in the workplace (Martin, 1990). Sometimes role encapsulation comes from the pressures outside of work, as even if a female police officer reports she has a good chance to be promoted, family and motherhood pressures can stop a female police officer from seeking more prestigious work (Wertsch, 2008). The role of "mother" also causes conflict as male police officers at work value female police officers taking on the role of 
"mother" because it meets their expectations of what a woman should be. Unlike the role of "mother," being an actual mother at home devalues female police officers as pregnancy and taking care of children might interfere with their job (Cowan \& Bochantin, 2009).

\section{Analysis}

This study uses qualitative analysis to analyze the data. The greatest benefit to qualitative analysis is that it is a powerful way to look at experiences of individuals and explore concepts that future research should address. One of the most useful methods for conducting qualitative data analysis is constructivist grounded theory. As a version of grounded theory, the constructivist approach focuses on how participants construct meanings and actions at specific places, times, culture and contexts (Charmaz \& Belgrave, 2012). This variant includes all of the foundations of grounded theory including conducting initial data analysis, immediate analysis of new ideas, constant comparisons from ideas to data, focusing on basic social processes, creating theoretical categories encapsulating the processes, theoretical sampling to check the created categories, and integrating the categories into a theoretical framework (Charmaz \& Belgrave, 2012). For this study, tentative categories discovered from the data are compared to the concepts of visibility, contrast/isolation, and assimilation/role encapsulation to evaluate their effectiveness in explaining token experiences.

\section{Research Questions}

Visibility and Performance Pressure. Female police officers should report that they experience higher visibility than male police officers and that mistakes made by any female police officer affect all female police officers. There are symbolic consequences 
for all female police officers when one female police officer fails or succeeds, further dividing women against each other (Kanter, 1993). They could report that they are singled out for promotion due to their gender alone, and the higher they go in the organization the more visibility they bring upon themselves. One female police officer's successes could put pressure on all female police officers in a group to conform, as the majority sees them as a group instead of individuals, and therefore the successful female police officer becomes the standard for all other female police officers in a department.

Research question 1. What performance pressures and double standards do female police officers perceive relating to their heightened visibility in a police department and do they report they are viewed as a collective instead of individuals and what strategies do female police officers employ to overcome these problems?

Contrast and Social Isolation. Female police officers should report that they are not included in the informal support networks inside police departments. This could include not being invited to social events off duty, not socializing with other officers on duty, and not having other officers volunteer support for service calls. Female officers are seen as different from the majority, who then exaggerate their own commonalities and differences from the female police officers. Female officers can potentially be seen as endangering the status quo, and separating them from the majority and each other lessens the danger of the majority.

Research question 2. What are the ways female police officers perceive they are socially isolated from the police culture and other female police officers?

Assimilation and Role Encapsulation. Female police officers should report that they are expected to fit a role created for them before they joined the police department. 
This could be the defeminized policewomen or the highly feminized policewomen (Martin, 1993), or more generally the "seductress," the "pet," the "iron maiden," or the "mother" Kanter discussed in 1977 (1993, p. 233-237). Facing stereotypes instead of being judged on their own merits is a problem to overcome potentially on a day to day basis. No matter what a female police officer achieves there should always be an entrenched ideal of what kind of work is appropriate for a female police officer. A female police officer would most likely be seen as using her sexuality, perceived "manliness," or her "inherent" nurturing manner as the only avenues to advance her career.

Research question 3. What roles do female police officers perceive they are expected to perform and what roles do female police officers report they should perform according to their own individual strengths and weaknesses?

\section{Summary}

Previous research has found indicators of tokenism, including its effects on job satisfaction (Krimmel \& Gormley, 2003) and promotional aspirations (Archbold \& Schulz, 2008), but the existing body of tokenism in policing is very small. Gustafson's (2008) attempt at a quantitative test of tokenism used three questions from a previous study that were not meant to evaluate tokenism and, it could be argued, have little to do with the three tokenism constructs he into which categorized them. Krimmel and Gormley (2003) focused on job satisfaction using the definition of a token group making up fifteen percent of less of a department. In doing so they found what could be the effects of being in a token group, but did not measure if the female police officers were subjected to problems associated with visibility, contrast, and assimilation. Archbold and Schulz (2008) specifically looked for female police officers' experiences relating to 
visibility, contrast/isolation, and assimilation/role encapsulation and their effects on promotional aspirations, but is the only study to effectively look at all three constructs. This study seeks to expand this small body of research by specifically evaluating the presence of token issues with visibility, contrast, and assimilation, as well as any effects they may have on female police officers. 


\section{CHAPTER IV}

\section{RESULTS}

The purpose of this study is to discover if experiences of tokenism were found in the stories of female police officers in this sample using qualitative analysis. These experiences of tokenism can be grouped around the concepts of visibility, contrast, and assimilation. This chapter will present the findings based on the analysis of the police officer's responses in two sections. The first section will briefly explain the sample and its characteristics. The second section will provide detail into the qualitative data relating to the research questions.

\section{Research Questions and Findings}

Question 1 - Visibility and Performance Pressure. What performance pressures and double standards do female police officers perceive relating to their heightened visibility in a police department and do they report they are viewed as a collective instead of individuals and what strategies do female police officers employ to overcome these problems? For this study, visibility was split into indicators relating to standing out, work harder for same recognition, and women treated as a group. All of these indicators were meant to cover the core aspects of visibility as well as finding more detail within the subthemes. In the recounting of their careers, a majority of the female officers felt they were more visible due to being female in a male dominated field. 
Standing out is one of the three major indicators of visibility white female officers described during their careers. It illustrated the ways in which female officers felt their gender distinguished them from their male counterparts, whether positively or negatively. Often female officers felt they stood out amongst men when they achieved positions dominated by male officers. One officer said, "We still to this day have not had another female cadet class president" and another officer noted, "I am the only female firearms instructor." A female officer promoted over male officers in positions where women have already had success in can also lead to greater scrutiny for female officers. A more tenured officer noted a promotion early in her career caused resentment among male officers. In her words, "You know I was only here two years and got promoted to detectives. That didn't go over easy well. You know a new person, especially a female, getting this cushy job." After a female officer has blended into the background of a department and has overcome male resistance, she felt hesitant to pursue opportunities elsewhere. An officer further on in her career described her distaste for ever transferring to a department without other women for support, "I can't imagine going to a municipality where you are [...] the only one (female officer). It's hard." At the intersection of gender and sexual orientation, a female officer can suffer from increased visibility and stress by being two tokens at once. A lesbian female police officer described her increased visibility as a female and homosexual token very simply as, " $I$ was the token lesbian."

Other officers responded to the stresses of standing out by changing their behaviors to avoid standing out by their gender. One younger officer would always report any small infraction or even a barely visible paint scrape on her patrol vehicle due to the 
fear that a citizen would identify her because she would be the only "female driver" at the police department. Another younger officer permanently changed the way she styled her hair to lessen her perceived femininity, "I always wear my hair in a bun in back because if I didn't the guys would give it to me. They'd say, 'Oh it's not tactical.' It's been in a bun for about three years. " A more tenured officer went to extremes to avoid perception she was a woman with different physiology, "For many years [...] I felt like I couldn't even take a sick day because it would be looked upon as a female problem." Finally, a younger officer summed up the negatives of standing out as a woman in policing by saying, "I would say there's no other job I've ever worked, even being in the military, that I ever felt my gender showed out more than my police work, and it completely surprised me." In her perception, the extreme masculinity required to be a paramilitary police officer surpassed the masculinity required to be a full military soldier.

Many other female officers viewed standing out as advantage to their careers and emphasized being a woman, "So what sets me apart? My gender does. And [...] it doesn't matter it's because of gender, because of race, because of a physical characteristic: It's an advantage if it gives you visibility. You can make it an advantage if you use that visibility [...] to your future." Another officer also found being a female officer gave her more opportunities if she allowed her gender to be emphasized, "[...] I was very unique. So I think I had the opportunity to do a lot of things that maybe others might not have had, in part because I think the department was showcasing me," but that same officer described the drawback to this attention, "You know, I looked good in uniform. But you know, sometimes you get frustrated because people didn't take you seriously." Not being taken seriously by other officers, male or female, can limit the 
entrance into prestigious and specialized divisions, where traditional masculinity and dominant behavior is perceived as necessary.

Another section of officers also found standing out is a positive for the public perception of female officers, both to the public and to young police recruits. Officers described the positive benefits to the public as, "[...] I think just showing that extra, that there is a female out there. That she is doing the job, you know" and "I've had them (citizens) come up and tell me they're glad to see me, and 'it's about time' kind of thing." Officers starting to become established in their careers and those already with some seniority both agreed that Standing out could be used to motivate young recruits and officers. An established female officer focused on the benefits of Standing out on motivating younger female recruits by saying, "I've always been really cognizant that what you do help other people see, 'See, she did it, I could do it too.' They can see there's someone like them, especially when I was the (high ranking training officer) for a while. I thought that was particularly important for recruits to see." One younger officer focused on the benefits for herself being visible and using it to distance herself from the "variety of females" that male officers might have worked around, "That's one of the reasons I just became an FTO because I was seen. There was a lot of people that came in, not that they're biased against me because a lot of guys sit back and watch me just because they never worked with a female before or they worked with a variety of females and they wanna see which kind I am. There's just a lot of-there's just some people who don't know how to act." Her actions could diminish the general bias against all female officers, but her motivation focuses on how her visibility would make working with male officers 
easier for herself. Despite perceived benefits, a major drawback of standing out is that failure is hard to manage when highly visible.

Some female officers felt their visibility also caused greater critique for mistakes. This occurs when female officers are punished more harshly than male officers for the similar mistakes. One officer described how errors women made were more visible, "I think [...] women stand a higher risk of being described in negative." She elaborated to say these were not errors unique to women but were "[...] errors that we all make." As for the lasting effects of making a mistake as a woman, the officer said, "If a woman screws up I think it has a tendency, reputation wise, to stay with her more easily than a male." Another officer told a story about another female at her class in the academy who had risen to be a high rank, but through one injury, "She got a reputation as a wimp." The officer telling the story also seemed to share in perpetuating the reputation of being a "wimp" as she said of the other officer, "She did a wimpy injury in defensive tactics." Mistakes are heightened as a female officer but their hard work and successes do not always stand out.

Another indicator of visibility was that women had to work harder for same recognition as men. Only two of the young female officers in this category said that they had gained acceptance early on and without exceptional circumstances. One of the officers said, "I think once they saw and knew that I could do it and I could probed that I could do it, then it (the resistance) stopped." The other reported, "You know being able to prove to them [...] yeah I can do this job just like you can do this job.” Their experiences were not common and most officers interviewed felt resistance throughout their careers. 
Many officers said they had to prove themselves repeatedly throughout their careers. The assumption is that these women were talking about having to prove their "worth" to other officers. As one officer said, "I do feel that you have to constantly go back out and nurture that acceptance." Other officers said they felt that moving from one job or location restarted the process of proving themselves, " [...] each time you go to a different location you have to prove yourself again and again and again." This same officer wanted to avoid proving themselves to a new set of male officers and staying "safe" in her current situation, "I don't have to go through any of the other crap [...] I have already been and experienced it all. I am safe, I am good, I am respected for what I do and [...] I'm accepted." Another officer said of moving or accepting a new job, "It's a continual process. You are never accepted based on your merits." To her, there is no accomplishment, award, or position that assures a woman would be respected in a new police department.

A set of female officers found that using violence was an effective way of gaining acceptance with male officers. Some officers reported having to "try double as hard [...] and not just in numbers as far as arrests, but at times I've had to get in any fights or pull out my gun" to make male officers accept her but she "was still kind of a step behind." One officer said she gained acceptance "[...] once the guys saw I was going to jump in and grab ahold of people and handcuff them and you know I wasn't afraid of that." This proof of embracing violence and physicality is seen in another officer's story as she says, "[...] if they didn't see me fight, they thought, 'Oh, she may run away." In an extreme example of having to use violence towards acceptance, a more tenured officer said, "I was almost killed in a hotel room. I had to use my gun on a 17 year-old. I think not that 
you hate to say it that way but I think the officers felt that, 'Well she can do the job. She did prove that she made it out of the hotel room alive and protected herself."

Rank was also not a guaranteed way of being accepted as a female officer. One officer remarked that women had to be, "working twice as hard to be considered half as good" and " no matter what you do they're going to talk about you and [if] a female gets promoted she slept with somebody, she sucked up." Another officer said after being promoted to sergeant, her master sergeant "questioned every decision that I wanted to make and you could tell he just did not like that I was in the position." Another high ranking officer said she found "sometimes is with ideas or proposals it seems like you have to fight to be heard" as a female administrator. Finally, one female officer responded to resistance to the legitimacy of her promotion by trying, and succeeding, to be the top score on a promotional exam. She said, "When I walked out of the test they were like, 'She is the one to beat."' Recognition for individual achievements among women is difficult but makes some sense as female officers are often seen by male officers as a group instead of individuals.

A final topic indicator of visibility was women were treated not as individuals but as a group. Many female officers told stories where male officers were paranoid by having too many women working together. Despite female officers tendencies to distance themselves from "other" women (as discussed later in this chapter), the invasion of women into the male dominance of policing was treated as a coordinated effort by male officers and administrators. On female officer's opinion on the matter was, "Of course you know if there's more than 2 women in a conversation, you know three, makes a conspiracy, so." Another officer backed this up with a story about earlier in her career 
where, “At that time they didn't want us taking vacations at the same time. They didn't want us on the same shift. They wanted us kind of spread out." Some of the officers attributed this nervousness in women working together to the perception amongst male officers that female officers will work against them, "The guys are [...] very nervous or [...] it bothers them when, you know, they have a lot of, you know, women. I don't know if they're just afraid I am going to get something they're not or I don't know." One higher ranking officer recalled being called the "Estrogen Mafia. [...] Because I was head of investigations, I had a female sergeant, and a female detective in there but it was called the Estrogen Mafia."

In another example of how women are treated as a group, a female officer in a high ranking training position related a story where she asked a range officer how a cadet was doing and he responded, "Oh fine, but the women are having trouble." After asking who specifically was having trouble she found that two men and only one woman was having trouble, but she had to ask those specific questions "to get them to realize what they were saying because they would lump women together." Despite statistical evidence that the male officer was aware of, he still chose to perceive all female recruits as inferior. Finally, a female officer rebelled against being lumped together with other women when "someone's like, 'You know, most women don't think that.' I'm not most women." Male officers treating female officers as a group becomes especially difficult when an officer makes a mistake.

One consequence of women being treated as a group was that one woman's failure affects all women. This was related to their increased visibility compared to men, "because there are few of us and she (a female officer) makes a mistake it becomes this 
big." One officer was taken aside to be warned about "other" female officers, "well this one had a problem with the last woman who worked here and this person over there in (City) had a problem, you know, so watch out for them." Most of the other officers were concerned with how these mistakes affected their reputation, "having that (other cadets this female officer assumes will fail) actually occurring lessens my credibility in my crew. " Lastly, a female officer expressed having to use physicality and violent behavior to regain credibility in the eyes of male officers because, "There was a female officer in (City), the guy ran from the car, she jumped in the car and locked the door. So, some people think if they don't see the hard-core one then they assume I'm automatically a wuss." Failures did not have to be individual or even current, but could be the perception that all women are like previous generations of female officers.

Female officers reported a responsibility to ensure a good reputation for female officers entering policing, "Which, you know, always makes it easier then for the next generation to come in." Another established officer backed this up be saying, "So when I screw up people are going to remember. Well that you know so and so woman, you now the one. Cause when I came here I was the one." A younger officer recounted how this affected the beginning of her career as she heard a "Story about two women, one was successful and the other was 'real lazy. '” Once again, she had to prove herself as a female officer instead of just a new officer.

Visibility was both a force to be harnessed to rise above the male dominance of policing but was more often discussed as a barrier to acceptance. Female officers had to prove themselves as competent and worthy of a role dominated by men, and often had to confront double-standards by working harder than men to achieve the same respect. 
Proving themselves was a continual process that could not only be derailed by a female officer's own mistakes, but the mistakes of any other female officer. Treating women as a single entity instead of unique individuals and deriding them all for any mistake was used as a method to divide women against each other. One strategy that female officers who rose through the ranks used was to emphasize their uniqueness and difference from men and weather the resistance they received. This was not a strategy that most female officers wanted to pursue and by buying into the idea of traditional masculinity as superior and using violence allowed women to gain acceptance but not excel beyond male officers. By attempting to blend in, these female officers sought to avoid any performance pressures visibility manifested, though this was not always the case. In the end, only 7 of the 38 female officers did not relay a story about dealing with visibility problems, but all of those women did encounter problems with contrast at one point or another in their careers.

Question 2 - Contrast and Social Isolation. What are the ways female police officers perceive that they are socially isolated from the police culture and other female police officers? Based on the framework of tokenism, the indicators used for identifying contrast in the female police officers' stories were dominants exaggerate differences, close ranks, women turn against each other, and response to the isolation through othering, de-feminizing or de-professionalizing. All but two of the female officers related a story during their career that described stark contrast leading to their isolation.

Dominants exaggerate differences without joking or harassment was described in few of the life experiences of the female officers and the common theme was male officers assuming the worst case scenario around a woman. One newer officer recounted 
male dominants assuming what a new female officer would act like, "the guys were worried that they weren't going to be able to say around me and watch their p's and q's. " This idea of a woman's presence disrupting the status quo of male policing was backed up by a more tenured officer recounting her need for shared experiences with other female officers, “You're not planning to overthrow anything, you're just kind of looking for that reinforcement." Another officer described her experience with assumptions of her need for children being put ahead of her policing duties as, "Everyone in the department thinks I wanna work a year, take a year off to have kids, work a year, take a year off to have kids, and do that for ten years." When these exaggerations go past simple assumptions, they cross over into harassment by male officers.

Dominants exaggerate differences often took the form of harassment or jokes intended to exaggerate differences in the female officer's careers. An established female officer recounted a story about having to indirectly confront another male officer who had a lingerie calendar in a common area. Because this was earlier in her career, she decided to put cut outs of clothes in the calendar. This was enough of a joke to the male officer to remove the calendar. Using this strategy, she sought to avoid direct confrontation which she believed would make her even more isolated and still affect small change. Another established officer avoided conflict with the dominant male group despite sitting "at a briefing and the shift commander would allow you to be the butt of the jokes at the table. And he would laugh too and think it was pretty funny." Again this officer felt that confronting the male officers would have isolated her further and heighten her contrast. Male harassment is not part of the distant past as the story of a younger officer who said, "I used to have the word 'Bitch' written on the hood of my car 
when I worked midnights." The same officer also said, "My vehicle, as of recently, has been turning up missing beginning of shift." These extreme examples did not lead the officer to retaliate in any manner and, instead, her thought was to avoid working midnights to avoid this behavior. One officer responded to the environment of listening to "crap that was really nasty" by getting "into the mix" saying it was "more of an acceptance thing" and that is didn't bother her. Her description of the things she was hearing as "crap that was really nasty" suggests she was bothered by it, but in her story is minimizing her reaction to display how accepted she has become by mimicking the male officer's behaviors. Another female officer accompanied by her supervisor directly confronted the harassment and "got emails from like everybody, you know, and there was one email that they sent about the dyke and the nigger. I was obviously one and my boss." Harassment is only one form of heightening contrast between the tokens and the dominants, where dominants closing ranks to isolate the token is another.

Closing ranks was the most common theme within contrast that female officers talked about it and can be summed up one officer's statement, "I think, of the things that has impeded me the most, is that police work is [...] a little bit of a boy's club and I'm not a boy." Other established officers held the same, more general view of societal hegemonic masculinity that "you're always gonna have the egos of people who just don't think women, you know, should do this or that." Male officers could also be very direct in isolating the female officers in stories such as, "I had this experience $[\ldots]$ when the sergeant told me that I didn't belong there" but also indirect by not inviting women to prestigious policing groups, "When my boss was here we used to go to the local chapter meetings, but it was a real struggle because, like I said, they weren't really inviting (to 
women). ” Informal social events can be a challenge as well as one officer recounted, “[...] I've never been invited on the fishing trips and I have never been invited to go to the ballgame." The same officer said that her Chief responded to finding out that she was informally gathering together with other women off duty by ordering her "never to do that again." A younger officer also recounted being separated from men off duty, "They go bike riding, go kayaking and all that stuff. We don't have all that." Even on duty male officers seek to separate themselves from female officers by refusing backup from the female officer and "immediately call to a male officer to assist."

Within the stories of the female officers related to closing ranks, the difficultly female officers have with police equipment that was designed specifically for men became very apparent. As a more tenured female officer said, "Uniforms, yeah. Uniforms are built for men, and if you're a woman who has curves, then you will have somewhat of a problem." Another officer coming out of training in the past related where a supply sergeant ordered her men's sizes and told her, “[...] if you have a man's job you will wear man's clothes." Younger officers still face these issues today as one said, "So I got my vest and the joke was that you could see my blood type through my shirt because it was so tight." Facilities are also an issue of the past that has bled into the present as a more tenured officer said, “In 1985 many facilities didn't even have men's and women's locker rooms, restrooms, uniforms. The equipment wasn't there and it's still very, it's limited even to this day." This was supported by a younger officer, "We have two bathrooms, but everyone uses both." One officer even pointed out techniques taught in training did not always work for women, "You know a guy could come across in a bullying kind of way, or very assertive, and I found that with my smaller stature, people 
would kind of just laugh at you." Along with equipment issues, pregnancy and childcare policies have also kept many women from seeking out or continuing careers in law enforcement.

Along with equipment designed for male officers, policies were also designed to accommodate men and ignored many female concerns such as the lack of a pregnancy policy, the lack of knowledge of the existence of a pregnancy policy, and the lack of childcare options. Older officers faced a lack of any policy including one officer who said, "the policy was not really a written policy until the female that is on now came on 13 years later [...] after I came on. " Another officer said that her chief at the time told her, "Well I can't have an officer here who can't perform the duties and I can't put you out on the street if you're pregnant. So get pregnant it's the end of your job." Today, instead of being threatened, younger officers interviewed said they were "not sure how they do that" and "I don't think they (the department) would know how it would work." Several other officers knew of a pregnancy policy, but the policy was not in writing. One older officer described her department's pregnancy policy as "informal" despite being written down. Another female officer was at a department that had never had a pregnant officer in uniform and, "Until a woman in uniform is pregnant, they haven't had to deal with it." One female officer cited the main fear of a lack of a policy, or one that will not support an officer enough, "because my fear was, I couldn't work. I needed money."

Female officers with children also face a lack of policies to make childcare a viable option. A younger officer summed up the dilemma facing female officers, "The shift work just kills people with kids" and she was skeptical if childcare would help because, "the parent has to come home." A marriage with two police officers can be 
even more challenging as a more tenured officer said, "It has always been an issue in my family only because my husband is a police officer." Two female officers have taken steps back in their careers to accommodate having a family. One said, "I'd get called in in the middle of the night because my husband at the time worked overnight midnight shift. So trying to find someone to come and stay with the kids if I got called in the middle of the night and it was just a hassle." Another officer took a more positive tone, "The decision best for my family hurt me professionally. You know, I lost money, I have to work weekends now. But you know you have to do what's best for your kid and I don't regret it for a second." Another version of closing ranks to bias hiring standards and job requirements for being a police officer against women.

Another major theme that came up was that the job requirements favored men and were not representative of police work. Many times the standards for police work do not fit the actual work of the police, keeping women from entering the police force. One older officer involved in training said, "I do exit interviews while they are here and one of the I mean the biggest issue is you know two of them came in and she was reminiscent of coat hanger I mean she's just long and tall and she's she couldn't life and she has no upper body strength." Another established officer reinforced the idea that women, and many men, have problems meeting the police standards in place, "We're (sp.) keeping they are failing at the physical. The physical agility part. And that's with men too." The problems with increasing the number of women in police work was the preference for military experience, "I started applying for jobs, and in the police world I didn't realize guys were getting veteran points and so with the little openings that they had, women were never falling in the top ten, because the veteran points were really just enough to 
teeter you the 3 to 5 to 10 points that they get." and paramilitary standards, “(Administrator name) got us all together one time and we were talking about you know some women shy away from the state police because it is paramilitary and try and soften that a little but it is what it is so." After successfully meeting current paramilitary standards for being a police recruit, many female officers are singled out by their trainers and field training officers.

Some female recruits felt isolated, persecuted, and outright hatred during their training academy and field training experiences. While there were examples of trainer and field training officer resentment, the stories were not common. One younger officer recounted her training experience, "[...] I just had the most horrendous time at the academy. The control tactics instructor was this massive six foot six, three-hundred pound meathead, muscle man. Whenever he would demonstrate something, he just loved ripping me out of my shoes. I'm like, 'Oh good you can pick on the five foot two girl. Why don't you pick on someone your own size. Anybody in the room can throw me.", Field training officers also targeted some female officers, as one older officer recounted, "And in fact my first training officer was the first day I came on the job I said I don't need any job this bad it was just miserable." "[...] he also told me that he was promised a promotion if he could get me to quit because they just didn't want women." Another younger officer felt her field training officer singled her out as, "his job was to $X$, axe me out. His job was to get rid of the weakest link. So he thought, 'Okay, she's a woman. I'm going to do my hardest to get rid of her." "' Even after training female officers could be shunned by male officers, though rare, "I still don't get spoken to by certain individuals. They don't speak to me. I still say 'hi' to them. You know I see them in the locker 
[inaudible] report [inaudible], 'Hey, what's up?' Nothing. Nothing, and they do it in front of people, so everyone knows." A more common theme than female officers being isolated from male officers was female officers shunning other female officers.

One strategy that Kanter (1977) suggested tokens used to align themselves more closely with the male dominants was distancing themselves from other tokens. Looking into this aspect of closing ranks, two related but distinct topics were talked about in the interviews of the female officers relating to how women responded to being isolated. Women turning against each other describes female officers intentionally turning on each other by the female officer herself or her experience with another female officer turning on other women. Response to the isolation by other-ing, de-feminizing, or deprofessionalizing looked at how women changed the way they saw themselves or other women in an attempt to gain acceptance into the dominant male officer group. Women turn against each other revolved around the idea that female officers did not find as much acceptance among other female officers as they expected. In a more extreme story, a more tenured officer described, "this experience when I remember I met my female counterpart up there who was on the road there were only two of us there at the time. And one of the male officers that I went to introduce myself and I stuck my hand out and said I'm (OFFICER NAME) and she turned her back and walked away." One younger officer described women in general as, "competitive with each other" whereas another young officer found it was not skewed, "there was some resistance with some females which I thought was odd, but there were several more that were willing to accept." The competition was not only amongst peers and when asked why younger female officers are not getting mentored, one officer said, "They are competition (to older female 
officers)." The reasons for female officers turning on each other could be due to individual preferences but many female officers in this sample distanced themselves from other female officers to try to align themselves more closely to male officers.

Some female officers used de-feminizing and other-ing to be more acceptable to the dominant male group. There were many examples of female officers pointing out the differences between themselves and "other" female officers and de-feminizing to distance themselves from most female attributes. Usually female officers used other-ing to imply that displaying anything feminine or related to being female had no place in policing. Another officer described some female officers as "giggly and wahoo" and describing policing as "not a pajama party." The same officer went so far as to call out a female officer for "dragging her breast pump to work with her."

Two officers, one older and one newer, attributed part of their longevity in policing to de-feminizing and being "just one of the guys." A newer officer implied that female officers who did not de-feminize would be more strongly associated with being a woman over being a police officer without witnessing it herself, "I don't like some of these female officers that have all the foo foo hairdos. I haven't witnessed it, but I would imagine they get treated more like or looked at as a woman first than an officer." Becoming too de-feminized can also cause female officers to separate themselves as a more tenured officer said, "there was another girl there (AT THE ACADEMY), but I wouldn't call her a girl. She wasn't a girl." Not all female officers find de-feminizing to be an easy process or emotionally satisfying.

One officer expressed discomfort through the pressure to de-feminize, "Early on in my career, I always felt like anything that emphasized the fact that I was a woman was 
bad, and I had to be as masculine as possible, but that was always uncomfortable for me." Another officer backed this up, but narrowed it to only patrol duties, "I think patrol is a different atmosphere. You don't have the ability to be as feminine as you might want." Finding a balance can be difficult for female officers and officer used humor to highlight the conflict female officers navigate, "I mean I wear boy's clothes every day and I have to have a sense of humor about it. " An established officer suggested female officers needed to be both "unattached and unemotional" but also that, "whatever happens when you get in the car and you break down and you cry that's good." The same officer seemed to break that creed relating to talking with male officers and said, "I joke and I laugh and I am a flirt and it's all good but that's where it ends." Using the strategies of other-ing, de-feminizing, and de-professionalizing female officers attempt to find their own place within the police culture. When these roles are challenged by what the dominant group expects them to perform, token female officers face assimilation and role encapsulation.

Women used a variety of strategies in order to reduce their contrast from the male expectations of policing and reducing their isolation from the police culture. Many officers, especially older ones, found themselves seeking friendship outside of policing and sought to separate their work lives from their private lives. During work there is little that women can do to reduce the contrast or isolation they feel and the stress that can come from it. First, women must find a way to enter policing despite entrance standards focused on male-dominated physical traits instead of police duties such as effective communication and patience. Then, they must make their way through academy and field officer training that can be openly against their presence. Finally, women have to find 
ways in order to minimize their "feminine" characteristics or association with other women. Often this last step is accomplished through female officers other-ing other female officers in an attempt to distance themselves from "giggly and wahoo" women or, in the experiences of some officers, any female officers in general. They also tended to use de-feminization techniques to conform to male standards and maximize their "masculinity" becoming, as a handful of officers described, "one of the guys."

Question 3 -Assimilation and Role Encapsulation. What roles do female police officers perceive they are expected to perform and what roles do female police officers report they should perform according to their own individual strengths and weaknesses? Assimilation indicators included being forced into stereotypical roles or paternalism, dead-end or undesirable assignments, and glass ceiling or reduced access to promotion. Stories of assimilation were found in most of the female officers careers ranging from male expectations of women's role in policing to female officers emphasizing what they believe women bring to policing that is unique to women.

Being forced into stereotypical roles or paternalism describes how male officers or supervisors expecting female officers to perform roles they believe women are good at instead of letting the female officers choose for themselves. One female officer's story demonstrates this role conflict between being a female and a police officer, "[...] isn't it possible to be both? To be an attractive female who's not, you know, a slut that's gonna go around and sleep with all these cops and that they don't work, but yet still be a super good cop on the street?" Often the role conflict occurred because the male officers or supervisors did not know how to assign a female officer, "And um like 'okay you can do the sex cases with the kids you know.', Sometimes the role conflict was caused by male 
officers not adjusting to differences in how women and men are raised to act. One officer described her chief's inability to handle emotions in an officer, "[...] I broke down in front of the chief and he didn't know what the hell to do. So you realize that he's like, 'You can go home.' Not 'it's ok.' It's stuff I really try and watch because they're really more protective of me, more so than they would be of the other guys and I try and. They're looking at me as a person, as a woman, at that time and not as a cop." In one occurrence forming a paternal relationship was not always against the female officer's will, as one officer described the relationship between a patrol captain and herself (an investigations caption), "And we developed the mom and dad kind of thing."

Male officers tended to be very open about their expectations of the roles that they believed female officers wanted to perform. Two younger officers were asked about their relationship status and if they wanted to have more children because they seemed to believe that the female officers only wanted to have children or date male officers. One of the officers was asked in their interview if they had a boyfriend and if they were going to marry him because as she describes the interviewers said, "'Well, there's some single guys in the department. We don't want you dating."' The other female officer describes a situation where 'because the chief asked me, 'How many kids do you plan on having?' I said, 'Well, one, that's an unethical question. You can't ask that. And two, I think 12 sounds like a really great number. I've got my two now and I've got ten more to go.' And that's where that rumor started. I'm not gonna have $12 \mathrm{kids}$, but if you ask a stupid question, you're gonna get an equally stupid answer. Cause it's none of his business." Two older officers recounted a male supervisor that was very open about his belief that female officers should not be treated the same as male officers. One officer described, 
“[...] we had a lieutenant who's long retired now, but when I was back in accreditation, he had some crazy ideas about women in policing and he thought we should wear bowties and skirts. "Even younger officers described male officers' belief that female officers needed extra help, "They were worried that I could handle myself. You know even if there was somebody else that was my backup, somebody else was closer that person even though they were not dispatched to me would come over here." Finally, one younger officer hoped that more women would ignore the male expectation that policing is a male profession, "I think more women need to realize that it's a great job, and there's always gonna be a couple of guys or a couple women or people who don't think women should be in it, and women bring a completely different aspect than men do." A more extreme form of this paternalism occurs when male officers or supervisors feel that female officers should be protected from danger and not allowed into the same situations as male officers.

Being kept out of "danger" was an uncommon form of assimilation and paternalism. This occurred when male officers felt that female officers need to be kept out of anything they perceived is dangerous, even if the female officer does not. This topic was surprisingly only identified by younger officers, and not in the stories of more established officers back when they were young. One of the officers said, "[...] one sergeant in particular forbid me, when he was working, for me to work one of the rougher areas of the city" while the other officer said that her chief would show up to all of her calls while he was off-duty. In both instances a male superior felt the female officer was not up to the task of policing potentially dangerous situations on her own. 
Another theme within assimilation was a women's role emphasized through teasing, touching, sexual comments, or other methods. Officers used sexual harassment to reinforce the perceived inferiority of female officers. One female officer reported her director used the term "policemen" instead of "police officers" and her belief that using that term was archaic. In her words, "policemen, and just think how unenlightened is that? I mean you're ignoring an entire chunk of your workforce and if you don't think they don't notice..." Another officer received critiques on her performance evaluation because she reported her sergeant said, “'You don't smile enough. We noticed you don't wear make-up."” After challenging the performance evaluation by going to her lieutenant, her original evaluation disappeared after she requested a copy for her own records.

Female officers often reported being perceived as a sexual object by male officers. One older officer said, "I think men when they have a woman come in they immediately size her up for dating potential." A younger officer was told that a male officer, "said he was gonna have sex with me before anyone else." Another officer recounted her story as being sexually harassed by a sergeant at her department, "I think they thought it was funny. I believe the statement was, well we are just going to add a little stress to your shoe. He took 60 days off. He should have been fired out." Two other officers had similar stories of being sexually harassed by an academy instructor and a training officer. One officer said that the academy instructor was telling male cadets places to "get laid" and then "He looks at me and goes, 'And honey if you have any problems getting laid give me a call' in front of the whole class." 
Sometimes female officers preferred or were assigned jobs that emphasized communication, empathy, or patience. This subcategory recorded when male or female officers expected female officers to take on jobs that required "feminine" characteristics or emphasized that women were better at these "feminine" qualities. In this subcategory, female officers were the leading force in supporting the belief that female officers were better than male officers at communication and empathy. Female officers suggested using empathy helped shape the way they performed their jobs. One officer suggested that "the nurturing thing" made her more effective at being assigned to a school than a male, "You know you nurture more in a school system than you do in uniform in a traffic division." Another female officer said empathy affected her leadership style, "I think as a leader I'm a bit more compassionate than my male counterparts. " Other officers said being a woman gave them over advantages over a male including having "a wider scope perspective on things," "multi-tasking," "thinking ahead," and "being able to pick up so much more."

The most mentioned benefit to being a woman in policing was being able to communicate more effectively than men. Two female officers summed a very common theme that "women depend on communication skills" and "women are going to be able to talk down a situation." Often female officers touted the benefits of communicating while deriding male officers for resorting to aggression or violence. As a younger female officer said, "I think I listen more and talk more and try to solve the problem rather than yelling." Another older officer supported this and expanded it to all the women in her department, "Where a guy might be more willing to be hands-on, where I would be like, 'Let's talk about this. What can I do to get you to cooperate?' This is the case with all the 
females on this department." Finally, a more tenured female officer stated that these qualities were "probably more nature than it's more natural to try to communicate." While women were the leading force in touting the benefits of communication and empathy, they were also likely to challenge the need for imposing "masculine" qualities or challenge the double-standards of aggression and assertiveness.

Many women tended to reject the view that female officers need to take on "male" characteristics and can use other methods to effectively police. As described in the emphasizing women's "strengths" topic, the ability to talk through situations and use empathy for the victims was a common belief in the female officers interviewed. Two officers described their view that aggression is ineffective for policing compared to keeping calm and using verbal techniques. One said, “[...] in the past I've been criticized because I've not been in a knock-down, drag-out fight. And my response was, 'Why do I need to be if I can walk up to John Doe and say, 'Excuse me sir you're under arrest. Would you please put these handcuffs on? '” The other officer ridiculed aggressive behavior passed from older male officers to newer male officers, "I think the guys want you to yell and the newer guys learn that from the older guys. I think it's silly. I laugh when I see them doing it and say, 'This is not doing anything., ', This also translated to female officers focusing on more empathic with victims compared to male officers, "People don't get in accidents on purpose. Yeah they leave their doors unlocked and go shopping, then their crap gets stolen and you wanna say, 'What'd you think?' That's what the male counterpart would say and I would be like, 'I'm really sorry that you're a victim, and we'll do the best we can.", 
There were several reasons female officers believed they needed to act differently than male officers. A more tenured officer believed that approaching situations differently than male officers was necessary because of the differences between traditional male and female physique. She stated, "You have got to be able to think a little bit differently than what the guys do. The guys will jump out and grab him and throw him onto the hood of the car." Another officer who emphasized empathy as part of being a female officer believed that male and female differences in temperament was also based on inherent differences. She said, "Well it's the nurturing thing in some women that I don't think we I don't get as hot mad quickly as I think some men do. Men I think are more like to fight and take things later sometimes and I think that's common with boys since the time they are five." Finally, another woman believed it was a product of learned behavior, "We bring a different perspective because a lot of men were brought up not to hit women. So sometimes when a woman is coming to the ... the chances of that woman getting in the altercation with a man is gonna be a lot less than it is for, you know, a woman." and hormonal differences, "And I think that men have a testosterone thing going on sometimes and they are more threatening than women, which is a benefit to us because if you don't think that I'm going to be able to handle myself, that gives me one up on you." As she notes in her statements both instances were beneficial for female officers, a common theme for female officers emphasizing "feminine" qualities.

Female officers also challenged the notion that double-standard set for describing males as assertive and women as aggressive. As one younger officer describes, "I come here to do my job and to go home safe and to make sure everybody else goes home safe. And some people don't like that in a woman. They feel that that's aggressive, and I say 
aggression and assertion are very closely tied together. And assertion in a man or aggression in a man can be viewed as assertion, and assertion in a woman can be viewed as aggression. So it's very gender specific in their own perception of what women should be like." A more tenured officer also related a story of a male colleague approaching her and saying, "'the problem is with you when women speak up they are considered aggressive. If you are a male you would probably be a captain because we would consider you very assertive and that's a good thing but women we just don't like them speaking up.,",

Dead-end or undesirable assignments illustrated women's experiences with being assigned to jobs that were not prized by co-workers. The stories in this category ranged from being denied access to special divisions, taking on sexual assault or juvenile assignments, or assignment to an undesirable position permanently. One older officer said she has been repeatedly denied access to a prestigious assignment, "Oh setbacks with specialized divisions yes. Wanting to move to a special division but not getting picked for it. You know it's one of those things where you just have to keep trudging forward." Several other female officers said they were assigned to sexual assault or juvenile cases despite their wishes. One officer described working, "on horrific cases for eight years. I got every bad case juvenile case."

Other female officers complained of the tendency to them handle sexual assaults because of victim preferences "If they (victims) have the choice, they would rather talk to me" and male officer expectations, "Because it (sexual assaults) involves females." Two officers described being placed in assignments where the female officer was stuck in positions they did not desire. The first officer told a story about the only other female in 
her department, "She's (the only other female in the department) an officer and she also has extra duties. She's in charge of our tows in our B and E vehicles. She has to take care of all of that and she hates it." The other officer described her own situation, "So I get promoted in August 03 then I am down here permanent." Female officer also experience dead-ends in their promotional aspirations and the "glass ceiling."

Glass ceiling or less access to promotion focused on experiences where female officers felt they were prevented from the same access to promotions as male officers. A prototypical example of this was a story where a younger officer was told by a female sergeant, "'you have really good skills and I don't think you're going to go far in this department. Not because you can't, but because of people at this department.", That sergeant encouraged the female officer to go to a different department to be able to, "do the things that I really want to do. "Finally, one female officer believed that woman not pushing more for getting promoted was, "unique to women I really do. I don't think the male counterpart thinks the same." As she described, "I don't think they would ever settle for the always the bridesmaid kind of thing in the support role." Changing this behavior, she believed helped her and could also help other female officers. According to another young officer, perseverance was not effective in overcoming this barrier to promotions, especially when an officer takes off time due to childbirth or other reasons, "I tried for detective seven times. I was denied all seven times. I was told that I did not have enough time, and I quote, 'because I took time off to have two children and I took time off due to worker's compensation' end quote from the Sarge. And he will not deny he said that." 
Female officers spoke against a "good old boy" mentality that prevented female officers from being promoted. One older officer told a story where a chief would not promote her over a man because, "He said, 'Well Rick's a boy.' I said, "Yeah, I've been doing his job.' He said, 'I can't promote you over a man. '” Another older officer said she believed some male officers, "have learned to be more accepting, racially sex or whatever, but I think actually some people just cover their tracks a little better." The ones that do cover their tracks she calls "the good old boys club" and that they are related to the "glass ceiling." Finally, stories of the "good old boy" club were not only told by older officers, suggesting that it is still in existence. A younger officer mentioned a good old boy club when she was asked why she was not getting promoted, "I think it's a good old boy thing personally. I think that we got a lot of nepotism, so that's an issue. I think it's a really big issue."

Female officers tended to be united in their belief that female officers were effective communicators and very patient, compared to male officers who utilized aggression and physicality. There was some overlap between suggesting that women needed to be "just one of the guys," emphasize the traditional strengths of being female, and devalue the traditional strengths of being male. This could be a balancing act for some, as they emphasize the traditional strengths of being female with the difficulties women face by not displaying dominant traditional male characteristics such as physicality or violence. 


\section{CHAPTER V}

\section{CONCLUSIONS, LIMITATIONS, AND IMPLICATIONS}

This study explored the experiences of tokenism within the careers of female police officers and identified emerging themes within their narratives. An important objective was finding a method of discovering tokenism, defined according to Kanter's (1977) theory, was present without directly asking if officers felt they were tokens. Female officers are well aware they are in a profession that is dominated by men and emphasizes the importance of aggression and physicality, behaviors traditionally associated with male behavior. The interviews of female officers asked women about their careers. Asking if a female officer she is a token does not allow that officer to describe her career in a detailed and nuanced fashion. Having an officer describe herself using the label of "token" forces her to accept being labeled a victim. It does not explore other stories where the female officer was treated as a token but she does not report it because to her it is just how she is treated every day and it does not allow her to describe how she negotiates being a police officer. Allowing the female officers to describe their careers on their own terms instead of asking them if they are tokens has yielded different results from past research. 


\section{Conclusions}

This study expands the research on tokenism in criminal justice by illustrating how prevalent experiences of tokenism are in female officers' careers. The results of this study were unique from past research in that evidence of visibility, contrast, andassimilation were found in all of the female officers' stories in one form or another. Unlike this study, previous research has only found limited evidence of the indicators of tokenism (Archbold \& Schulz, 2008; Belknap \& Shelley, 1992; Gustafson, 2008; Krimmel \& Gormley, 2003). The most common aspect of tokenism that female officers, in this study, encountered was police culture closing ranks against adapting policing for women. Most frequently, this involved police departments being hesitant to provide equipment designed for women, creating written policies for pregnancy, maternity leave, and childcare, and educating male and female officers about these policies. Even women who had very positive experiences being police officers often reported being unaware of written policies for pregnancy and maternity leave or having to deal with equipment designed for men. Regarding visibility, some female officers reported using their increased visibility to advance their careers or become role models. Unfortunately, not all female officers were able to harness visibility. Many officers sought to distance themselves from other women to avoid being associated with other women's mistakes, thus increasing contrast and isolation. Role encapsulation often took the form of women promoting the idea that "feminine" characteristics were positive and "masculine" characteristics were negative for police officers. This was another example of women using a token concept to promote the benefits of being a female officer instead of always being a negative. 
Yoder (1991) and Zimmer (1988) suggested that using a gender-neutral ratio ignores societal gender discrimination and this study finds support for this. All of the women in this study described being treated as a token in some way, either by standing out amongst male officers, being isolated from other male or female officers, or by being forced or accepting a role traditionally defined as feminine. More tenured officers tended to be more frank and detailed in their accounts of tokenism compared to the younger officers interviewed. As some of these tenured officers expressed, they were able to be more open because they felt more safe and respected at the more advanced stage in their careers and had come to terms with their increased visibility instead of hiding from it. The officers who had few or only a single story describing a moment of tokenism were much more guarded and brief in their responses compared to the more tenured officers.

Female officers in this study heavily favored, what they believed to be a woman's advantage, using communication skills and devalued the more masculine approach of intimidation and violence. While these beliefs did reinforce gender stereotypes, they also suggested that female officers have valuable skills that could increase police compliance while decreasing the use of violence. Choosing to ignore these benefits over using intimidation to gain compliance increases liability and calls into question the current standards for hiring officers. As suggested by higher ranking and more tenured officers, physical fitness is incredibly important to being a police officer, but so too is being able to talk your way out of using force. Women in this study often found ways to match or adapt the physicality of male officers and, if women are typically better communicators in this society, it would reason that they would also be hired at a much higher rate than they are today. Future research should focus on whether male and female officers expect 
these traditionally feminine qualities of communication and empathy to be preferred by female officers only or if both genders value them. The findings from this study suggest that female officers value such characteristics, but looking at both genders would yield more information on perspectives and the descriptive value of the concept of assimilation in tokenism. There is also much research still to be done by gathering more stories of female officers from departments of different sizes and female to male ratios. This study suggests the fifteen percent ratio Kanter (1977) defined for a token group is not important in describing female officer's encounters with standing out due to their gender, being isolated from broader police culture, and having to take on traditionally defined feminine roles. If tokens are defined by being less than fifteen percent of a group, then for the future a new concept that better describes a female officer's career experiences with gender discrimination should be created instead of using the word token. Women entering policing do not always accept the negatives of being a token and can embrace standing out or expectations of having greater communication skills than male officers. Instead of being token female officers, these women are police officer exemplars which future women can aspire.

Archbold and Schulz's (2008) study was the most similar to the findings in this research, as women did report they had to work harder, were more likely to report not feeling isolated, and typically did not feel their gender was a barrier to promotion. Unlike Archbold and Schulz (2008), this study looked further into the officer's life stories to illuminate stories where heightened contrast was an issue and they were expected to assimilate into certain roles. Officers in this research may not have felt they were socially isolated, but they often reported police departments not having policies to handle the 
issues of equipment designed for women and policies regarding childcare or pregnancy. Even officers who did not report issues with reaching a "glass ceiling" reported feeling that men and women were different and women relied more on communication and empathy. Future research should focus on the retention rates and percentage of female officers between departments that have written pregnancy policies, childcare assistance, and access to equipment designed for women. This study suggests that having these policies may encourage women to join the police ranks and may designate a department as a progressive department. It may also help to retain officers with families.

Belknap and Shelley's (1992) study found stress increased from gender issues and increased visibility, including the need for female officers to constantly prove themselves and confront sexism in their departments. This study found that many women reported having to work harder than men, however instead of it causing only stress, it also provided motivation to be better and to further their careers. These female officers had harnessed a major pillar of tokenism (visibility) and had found how emphasizing their gender had given them new opportunities they might not have had if they tried to be "one of the guys." This was not always an option for women interviewed and was not common enough to suggest that the "glass escalator" that some men use in traditionally female jobs would work for most female police officers (Williams, 1992; Williams, 2013).

In the stories of the female officers, avoiding or embracing visibility heavily influenced their success in seeking out promotions. Female administrators are women who have fought resistance against both women in policing and, more impressively, women taking positions of power over men in a male dominated profession. Many female officers who had not sought out administrative positions often had the mindset of 
becoming "one of the guys" and avoiding being seen as women. Unlike these officers seeking to minimize their differences from men, women who have achieved administrative positions would never be able to be "one of the guys" and would always stand out among their peers due to their rank and gender. The stories of successful female administrators tended to include a belief that working twice as hard as men to be equal was necessary and emphasizing the strengths of being a female instead of avoiding being seen as female. Future research into the harnessing or rejection of one's gender could uncover valuable insight into how gender affects officers' careers (Rabe-Hemp, 2009).

\section{Limitations}

The major limitation of this study is the composition of the female officers interviewed. First, the composition of the sample was heavily skewed towards white women and had an unrepresentative amount of administrators in the sample. The racial composition is ninety-two percent white, leaving for an incredibly small representation of any other groups. This is a challenge that would be almost impossible to avoid as it speaks to the nature of being a vastly underrepresented token group. Correcting this imbalance, so that it more closely resembles the actual racial percentages, would be helpful to identify any challenges non-white tokens face. Studies into tokenism could also focus on one underrepresented group at a time to ensure that group's voice is heard. Next, administrators were heavily overrepresented over line officers. Including more line officers could change the composition of the responses greatly as they have either avoided promotion or have not had the opportunity to seek it. As discussed earlier, administrators in this sample were much more open and detailed in the descriptions of their careers than less tenured officers. They have positions of power and often network 
more frequently than line officers, alleviating fears of retribution and career isolation. Also, administrators often had memberships with national organizations that promoted their networking. Future studies should evaluate membership into these national organizations and determine the extent to which memberships affects officers' experiences with the three pillars of tokenism. Finally, there was little geographical variation which would heavily affect police and community culture. Future research should look across the country to see how cultural values help or hinder the inclusion of female officers into broader police culture.

\section{Implications}

The indicators of tokenism found in this study suggest that there are common and identifiable issues that female officers face across several departments. Unfortunately, many of the obstacles that female officers face have been around since women gained entry into policing, but most are easily solved. With the Internet and the growing body of law enforcement gear, it would be an easy fix for most departments to properly equip their female officers with uniforms, tools, and firearms. Pregnancy, maternity leave, and paternity leave could also be easily addressed by police departments with a formal, written policy and educating their officers during training. Childcare is not easily solved, as it can be very costly, especially for smaller departments. Future research should focus on these costs and their relationship to departmental spending. If money could be reduced from equipment that is unnecessary and costly, it could offset the cost of childcare, which would benefit both men and women with families. The tendency for female officers to choose to isolate themselves from other female officers is another difficult issue to solve. Female officers in this study, who gained higher rank, also tended to be associated with 
police associations or groups that helped them to network with other female officers or administrators. Mentoring was also mentioned by established officers for integrating more female officers into police culture and therefore decreasing isolation. Future research could focus on this connection and evaluate if mentoring reduces the appearance of the three pillars of tokenism in female officers' careers.

The major implication of this study is that tokenism is too complex to be simplified into one simple question. As this study demonstrated, as tokenism affected every aspect of a female police officer's career. Gustafson's (2008) study is a strong example where using a single close-ended question was deemed sufficient to discover if tokenism was present. Unfortunately, these questions did not fully represent any aspect of tokenism. Gustafson's measures of visibility and assimilation could be easily confused with other characteristics such as work ethic, physical fitness, formal or informal connections, or others. Being treated differently does not identify tokenism. Being treated as a group, instead of an individual, because of gender, race, or sexual orientation does. As much as past research has referenced the idea of the token officer, there are few studies that actually looked for the pillars of tokenism that Kanter (1977) outlined in her original work. The value of this study was that it looked for the presence of the construct of tokenism and this research should be used as a new starting point to for evaluating the explanatory value of the theory of tokenism, or refining it into something that better explains the experiences of underrepresented groups. The predictive value of a group comprising fifteen percent at an agency being treated as tokens was not as universal. One explanation for this could be that looking at police departments as individual entities ignores the larger societal expectations of what it means to be a police 
officer. This shared societal image can be influenced by the presentation of police officers on TV, movies, and the Internet as much as it could be a belief passed down through generations. Every female officer in this study worked in one way or another to prove that female officers were as good as or better than their co-workers. Some female officers in this study worked from within policing to include and mentor the next generation of female officers, but they are few. In conclusion, future research should elaborate on how female officers are treated as tokens and if this is universal to all underrepresented groups. Research should focus discovering any strategies women can use to harness tokenism for their career advancement or strategies to avoid its effects. In addition to more research within criminal justice, tokenism research on men in traditionally female-dominated careers would find any gender-specific qualities of tokens. It remains to be seen if tokenism is the cause of stress for female police or if it is only a symptom of a much broader problem. 


\section{REFERENCES}

Archbold, C. A. \& Hassell, K. D. (2009). Paying a marriage tax: An examination of the barriers to the promotion of female police officers. In K. D. Hassell, C. A. Archbold, \& D. M. Schulz (Eds.), Women and policing in America: Classic and contemporary readings (pp. 103-123). New York, NY: Wolters Kluwer Law \& Business.

Archbold, C. A. \& Schulz, D. M. (2008). The lingering effects of tokenism on female police officers' promotional aspirations. Police Quarterly, 11(1), 50-73.

Belknap, J. \& Shelley, J. (1992). The new lone ranger: Policewoman on patrol. In K. D.

Hassell, C. A. Archbold, \& D. M. Schulz (Eds.), Women and policing in America: Classic and contemporary readings (pp. 332-355). New York, NY: Wolters Kluwer Law \& Business.

Bochantin, J. E. \& Cowan, R. L. (2008). On being "one of the guys": How female police officers manage the tensions and contradictions in their work and their lives. Ohio Communication Journal, 46, 145-169.

Bureau of Labor Statistics, U.S. Department of Labor (2012, May 1). Women as a percent of total employed in selected occupations, 2011. The Economics Daily. Retrieved from http://www.bls.gov/opub/ted/2012/ted_20120501.htm

Charmaz, K. \& Belgrave, L. L. (2012). Qualitative interviewing and grounded theory analysis. In J. F. Gubrium, J. A. Holstein, A. B. Marvasti, \& K. D. McKinney 
(Eds.), The SAGE Handbook of interview research: The complexity of the craft (pp. 347-365). Thousand Oaks, CA: SAGE Publications, Inc.

Cowan, R. L. \& Bochantin, J. E. (2009). Pregnancy and motherhood on the thin blue line: Female Police Officers' perspectives on motherhood in a highly masculinized work environment. Woman and Language, 32(1), 22-30

Gustafson, J. L. (2008). Tokenism in policing: An empirical test of Kanter's hypothesis. Journal of Criminal Justice, 36, 1-10.

Haarr, R. N. (1997a). Patterns of interaction in a police patrol bureau: Race and gender barriers to integration. Justice Quarterly, 14(1), 53-85.

Haarr, R. N. (1997b). "They're making a bad name for the department”: Exploring the link between organizational commitment and police occupational deviance in a police patrol bureau. Policing: An International Journal of Police Strategy and Management, 20(1), 786-812.

Haarr, R. N. (2005). Factors affecting the decision of police recruits to "drop out" of police work. Police Quarterly. Dec2005, Vol. 8 Issue 4, p431-453. 23p. 3DOI: $10.1177 / 1098611103261821$

Haarr, R. N. \& Morash, M. (2013). The effect of rank on police women coping with discrimination and harassment. Police Quarterly, 16(4), 395-419.

Harrington, P. E. (2002). Advice to women beginning a career in policing. Women \& Criminal Justice, 14(1), 1-13.

Hassell, K. D., Archbold C. A. \& Stichman, A. J. (2011). Comparing the workplace experiences of male and female police officers: Examining workplace problems, 
stress, job satisfaction and consideration of career change. International Journal of Police Science and Management, 13(1). 37-53.

Higgens, L. (1950). Women police service. In K. D. Hassell, C. A. Archbold, \& D. M. Schulz (Eds.), Women and policing in America: Classic and contemporary readings (pp. 10-15). New York, NY: Wolters Kluwer Law \& Business.

Kanter, R. M. (1977/1993). Men and women of the corporation. New York: Basic Books. Kingshott, B. F. (2013). Revisiting gender issues: Continuing police reform. Criminal Justice Studies, 26(3), 366-392.

Krimmel, J. T. \& Gormley, P. E. (2003). Tokenism and job satisfaction for policewomen. American Journal of Criminal Justice, 28(1), 73-88.

Langton, L. (2010). Crime data brief: Women in law enforcement, 1987-2008. Bureau of Justice Statistics. Retrieved from http://bjs.ojp.usdoj.gov/index.cfm?ty=pbdetail\&iid=2274

Leevy, J. R. (1948). The role of the police matron. In K. D. Hassell, C. A. Archbold, \& D. M. Schulz (Eds.), Women and policing in America: Classic and contemporary readings (pp. 8-10). New York, NY: Wolters Kluwer Law \& Business.

Lonsway, K. A. (2006). Are we there yet? The progress in one large law enforcement agency. Women \& Criminal Justice, 18(1/2), 1-47.

Martin, S. E. (1979). Policewomen and policewomen: Occupational role dilemmas and choices of female officers. In K. D. Hassell, C. A. Archbold, \& D. M. Schulz (Eds.), Women and policing in America: Classic and contemporary readings (pp. 133-146). New York, NY: Wolters Kluwer Law \& Business. 
Martin, S. E. (1980). Breaking and entering: Policewomen on patrol. Berkeley, CA: University of California Press.

Martin, S. E. (1990). On the move: The status of women in policing. Washington, DC: Police Foundation.

Martin, S. E. (1994). "Outsider within" the station house: The impact of race and gender on Black women police. In K. D. Hassell, C. A. Archbold, \& D. M. Schulz (Eds.), Women and policing in America: Classic and contemporary readings (pp. 151173). New York, NY: Wolters Kluwer Law \& Business.

Melchionne, T. M. (1967). Current status and problems of women police. In K. D. Hassell, C. A. Archbold, \& D. M. Schulz (Eds.), Women and policing in America: Classic and contemporary readings (pp. 16-21). New York, NY: Wolters Kluwer Law \& Business.

Morash, M. \& Haarr, R. N. (2012). Doing, redoing, and undoing gender: Variation in gender identities of women working as police officers. Feminist Criminology, $7(1), 3-23$.

Rabe-Hemp, C. (2008). Survival in an "All Boys Club": Policewomen and their fight for acceptance. In K. D. Hassell, C. A. Archbold, \& D. M. Schulz (Eds.), Women and policing in America: Classic and contemporary readings (pp. 377-397). New York, NY: Wolters Kluwer Law \& Business.

Rabe-Hemp, C. (2009). POLICEwomen or PoliceWOMEN? Doing gender and police work. Feminist Criminology, 4(2), 114-129.

Rabe-Hemp, C. (2011). Exploring administrators' perceptions of light-duty assignment. Police Quarterly, 14(2), 124-141. 
Remmington, P. W. (1981). Policing: The occupation and the introduction of female officers. Washington, DC: University Press of America, Inc.

Sass, T. R. \& Troyer, J. L. (1999). Affirmative action, political representation, unions, and female police employment. Journal of Labor Research, 20(4), 571-587.

Schulz, D. M. (1993a). From policewomen to police officer: An unfinished revolution. In K. D. Hassell, C. A. Archbold, \& D. M. Schulz (Eds.), Women and policing in America: Classic and contemporary readings (pp. 39-51). New York, NY: Wolters Kluwer Law \& Business.

Schulz, D. M. (1993b). Policewomen in the 1950s: Paving the way for patrol. In K. D. Hassell, C. A. Archbold, \& D. M. Schulz (Eds.), Women and policing in America: Classic and contemporary readings (pp. 21-39). New York, NY: Wolters Kluwer Law \& Business.

Schulze, C. (2010a). Family leave and law enforcement: A survey of parents in U.S. police departments. Critical Criminology, 19, 137-153.

Schulze, C. (2010b). Institutionalized masculinity in US police departments: How maternity leave policies (or lack thereof) affect women in policing. Criminal Justice Studies, 23(2), 177-193.

Wertsch, T. L. (2008). Walking the thin blue line: Policewomen and tokenism today. Women \& Criminal Justice, 9(3), 23-61.

Wexler, J. G. (1985). Role styles of women police officers. Sex Roles, 12(7/8), 749-755. Whetstone, T. S. (2001). Copping out: Why police officers decline to participate in the sergeant's promotional process. American Journal of Criminal Justice, 25(2), 147-159. 
Whetstone, T. S. \& Wilson, D. G. (1999). Dilemmas confronting female police officer promotional candidates: Glass ceiling, disenfranchisement or satisfaction? International Journal of Police Science and Management, 2(2), 128-143.

Williams, C. L. (1992). The glass escalator: Hidden advantages for men in the "female" professions. Social Problems, 39(3), 253-267.

Williams, C. L. (2013). The glass escalator, revisited: Gender inequality in neoliberal times, SWS feminist lecturer. Gender \& Society, 27(5), 609-629.

Yoder, J. D. (1991). Rethinking tokenism: Looking beyond numbers. Gender \& Society, $5(2), 178-192$.

Zimmer, L. (1988). Tokenism and women in the workplace: The limits of gender-neutral theory. Social Problems, 35(1), 64-77. 